\title{
Cytochrome $c$ at Charged Interfaces. 1. Conformational and Redox Equilibria at the Electrode/Electrolyte Interface Probed by Surface-Enhanced Resonance Raman Spectroscopy ${ }^{\dagger}$
}

\author{
Peter Hildebrandt*,t and Manfred Stockburger \\ Max-Planck-Institut für Biophysikalische Chemie, Abteilung Spektroskopie, D-3400 Göttingen, FRG \\ Received December 2, 1988; Revised Manuscript Received April 14, 1989
}

\begin{abstract}
The structure and the electron-transfer properties of cytochrome $c$ (cyt $c$ ) adsorbed on a silver electrode were analyzed by surface-enhanced resonance Raman spectroscopy. It was found that the adsorbed cyt $c$ exists in various conformational states depending on the electrode potential. In state I the native structure of the heme protein is fully preserved and the redox potential ( $+0.02 \mathrm{~V}$ vs saturated calomel electrode) is close to the value for cyt $c$ in solution. In state II the heme iron exists in a mixture of five-coordinated high-spin and six-coordinated low-spin configurations. It had been shown that these configurations form a thermal equilibrium [Hildebrandt, P., \& Stockburger, M. (1986) J. Phys. Chem. 90, 6017]. It is demonstrated that these equilibria strongly depend on the charge distribution within the electrical double layer of the silver electrode/electrolyte interface, indicating that the changes in the coordination shell are induced by electrostatic interactions. The structural alterations in state II are apparently restricted to the heme crevice, which assumes an open conformation compared to the close structure in state $I$. This leads to a strong decrease of the redox potentials, which were determined to be -0.31 and $-0.41 \mathrm{~V}$ for the five-coordinated high-spin and six-coordinated low-spin configurations, respectively. On the other hand, gross distortions of the protein structure can be excluded since the reversible proton-induced conformational change of cyt $c$ as found in solution at low $\mathrm{pH}$ also takes place in state II of the adsorbed cyt $c$. The linkage of cyt $c$ molecules to the surface is mediated by charged amino acid groups, and it depends on the potential which groups are thermodynamically favored to form such a molecular binding site. The conformational states I and II, which are in a potential-dependent equilibrium, therefore refer to two different molecular binding sites. At potentials below zero charge $(<\sim-0.6 \mathrm{~V})$ a rapid denaturation of the adsorbed cyt $c$ is noted, which is reflected by drastic and irreversible changes in the surface-enhanced resonance Raman spectrum. Our results are discussed on the background of previous electrochemical studies of cyt $c$ at electrodes.
\end{abstract}

C ytochrome $c$ (cyt $c)^{1}$ is an essential component of the mitochondrial respiratory chain (Dickerson \& Timkovich, 1975). It acts as an electron transporter between the membrane-bound enzyme complexes cytochrome reductase (cyt red) and cytochrome oxidase (cyt ox). In the terminal step of this reaction sequence cyt ox utilizes four electrons to reduce oxygen to water. The enzymatic electron transduction is coupled to the synthesis of ATP, the ultimate source of chemical energy for metabolic processes.

Despite extensive studies, the detailed mechanism of the electron-transfer reactions of cyt $c$ and its biological redox partners is far from being fully understood (Pettigrew \& Moore, 1987). But it is well established that electrostatic interactions play a crucial role in these redox processes. It is known that cyt $c$ forms tight complexes with cyt ox and cyt red prior to the electron transfer. On the basis of kinetic studies using chemically modified cyt $c$ derivatives, it had been shown that it is the lysine-rich domain around the heme crevice by which cyt $c$ is docked to the negatively charged binding domains of cyt red and cyt ox (Smith et al., 1977; Speck et al., 1979; Koppenol \& Margoliash, 1982; Rieder \& Bosshard, 1980). On the other hand, it is still an open question if the strong electrostatic forces that hold together these complexes

\footnotetext{
This work was supported in part by the Deutsche Forschungsgemeinschaft.

* To whom correspondence should be addressed.

? Present address: Max-Planck-Institut für Strahlenchemie, Stiftstr. 34-36, D-4330 Mülheim/Ruhr, FRG.
}

may induce structural changes in the heme proteins and thus affect the electron-transfer pathways and mechanisms. Recent circular dichroism and magnetic circular dichroism experiments had revealed spectral changes of cyt $c$ after binding to cyt ox (Weber et al., 1987). These results were interpreted in terms of alterations of the heme-protein interactions. However, a detailed picture of the underlying molecular changes could not be given. On this background it was desirable to analyze in more detail how electrostatic interactions may affect the structure of cyt $c$. In the present paper we addressed this issue by studying the structure and electrontransfer properties of cyt $c$ adsorbed on the silver electrode. The basic idea of this approach is that both electrodes and biomembranes at their aqueous interfaces develop electrical double layers which exhibit electric fields of comparable strengths. Thus, the proteins adsorbed at these interfaces experience similar electrostatic forces. Hence, the electrode/electrolyte interface may be regarded as an appropriate model system to mimic the electrostatic interactions during the physiological redox processes at the mitochondrial membrane.

\footnotetext{
I Abbreviations: RR, resonance Raman; SERR, surface-enhanced resonance Raman; cyt $c$, cytochrome $c$ (the indices I, II, and $\mathrm{N}$ denote the conformational states I and II of the adsorbed cyt $c$ and the native form of the dissolved cyt $c$ ); $\mathrm{cyt}_{\text {dena }}$ denatured cyt; $6 \mathrm{cLS}$, six-coordinated low spin; 5cHS, five-coordinated high spin; 6cHS, six-coordinated high spin; $E_{\text {pzc }}$, potential of zero charge; cyt red., cytochrome reductase; cyt ox., cytochrome oxidase; $\mathrm{CV}$, cyclic voltammetry.
} 
The silver electrode/electrolyte system offers the advantage that the structure and reactivity of the adsorbed molecules can be studied by surface-enhanced Raman (SER) spectroscopy (Cotton, 1985, 1988; Koglin \& Sêquaris, 1986). The sensitivity of SER spectroscopy results from the strong enhancement of the Raman scattering by up to 6 orders of magnitude that is observed for molecules adsorbed on rough silver, gold, or copper surfaces. In the case of cyt $c$ the sensitivity of this technique can be further improved. When the excitation line is in resonance with an electronic transition of the heme, those Raman bands are enhanced that originate from the heme chromophore, while the Raman bands of the protein matrix remain too weak to be detected in such a resonance Raman (RR) spectrum (Spiro, 1983). For cyt $c$ adsorbed on a silver electrode both the molecular RR and the SER effect can combine [surface-enhanced resonance Raman (SERR)], so that it is possible to selectively probe the vibrational spectrum of the heme group even at (sub)monolayer coverages. This technique had successfully been applied to study a variety of heme proteins adsorbed on Ag electrodes or colloids (Cotton et al., 1980, 1981; Taniguchi et al., 1984; Smulevich \& Spiro, 1985; Hildebrandt \& Stockburger, 1986a, 1989a; de Groot \& Hester, 1987; Niki et al., 1986, 1987; Kelly et al., 1987; Hildebrandt et al., 1988a; Wolf et al., 1988; de Groot et al., 1988).

In our previous work (Hildebrandt \& Stockburger, 1986a) we had shown that adsorption of cyt $c$ on colloidal silver ( $\mathrm{Ag}$ sol) is accompanied by structural changes of the coordination shell of the heme iron. The native low-spin (LS) configuration is transformed to a mixture of LS and high-spin (HS) states. Both configurations are in a thermal equilibrium in which the LS form is prevailing at low temperature. It was proposed that these structural distortions which were observed for both oxidation states, $\mathrm{cyt}^{3+} c$ and $\mathrm{cyt}^{2+} c$, result from electrostatic interactions between the charged Ag surface and the heme group.

In the present paper we have analyzed the structure and the electron-transfer reactions of cyt $c$ adsorbed on the Ag electrode. It turned out that on the surface cyt $c$ exists in different conformational states depending on the electrode potential. It will be shown that these states differ with respect to the spin and ligation state of the heme iron and the conformation of the heme pocket. Recording SERR spectra as a function of the electrode potential permitted a quantitative analysis of the redox processes of the different conformers. Thus, it was possible to elucidate structure-function relationships of cyt $c$ in the electrode/electrolyte interface.

\section{Materials and Methods}

SERR spectra were measured with a rotating cylinder electrode that offers the advantage to avoid local heating of the sample by the exciting laser beam (Hildebrandt et al., 1988 b). Such a device turned out to be crucial for the accurate analysis of the redox and conformational equilibria of the adsorbed cyt $c$. The design of the electrode used in this work is shown in Figure 1A. The silver ring (Heraeus, 99.95\% purity) with a radius of $2 \mathrm{~cm}$ is mounted in a Delrin holder that is screwed into the rotating shaft. Thus, the silver ring could easily be removed for cleaning and polishing. The stainless steel shaft, which is fixed by two precision bearings to the Delrin housing, serves as the conductor. It is insulated against the solution by a Delrin sleeve and contacted to the potentiostat (Wenking Model POS 73, Bank, Göttingen) via four graphite brushes. A rubber tube connects the rotating shaft with the shaft of the DC motor that provided a rotational frequency between 2 and $70 \mathrm{~Hz}$. All metal and Delrin com-

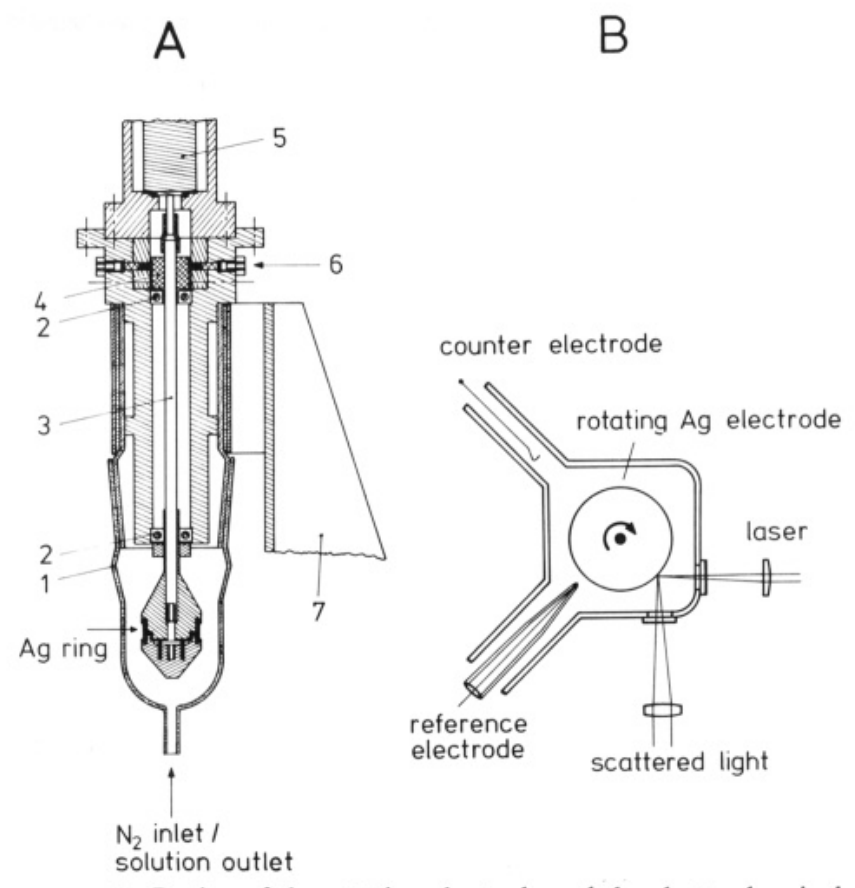

FIGURE 1: Design of the rotating electrode and the electrochemical cell. (A) (1) Glass cell; (2) precision bearings; (3) rotating shaft; (4) copper ring; (5) DC motor; (6) graphite brushes; (7) metal stand. (B) Optical pathway.

ponents of the electrode system were machined to a high precision so that the mechanical whobbling of the silver ring during rotation was less than $3 \mu \mathrm{m}$. During the SERR experiments the electrode was rotated with $15 \mathrm{~Hz}$.

A saturated calomel electrode served as the reference and a platinum as the counter electrode. All potentials cited in this paper refer to the saturated calomel electrode (SCE).

The exciting laser beam (413-nm line of a $\mathrm{Kr}^{+}$laser, Coherent, $2000 \mathrm{~K} ; 457-\mathrm{nm}$ line of an $\mathrm{Ar}^{+}$laser, Coherent, CR-15) was focused on the Ag surface by a cylindrical lens to a rectangular shape of about $5 \mathrm{~mm} \times 0.1 \mathrm{~mm}$. The laser power at the sample was $20 \mathrm{~mW}$, corresponding to $4 \mathrm{~W} / \mathrm{cm}^{2}$. A $90^{\circ}$ scattering geometry was used (Figure 1B). The optical alignment was achieved by moving the housing of the cell, which was fixed on an $x, y$ table. The scattered light was focused to the entrance slit of a Spex $0.75 \mathrm{~m}$ double monochromator (Model 14018). In RR experiments that were carried out with a rotating quartz cell, a polarization scrambler was placed in front of the entrance slit. For light detection an EMI photomultiplier (Model 9659 QB) and an Ortec photon counting device were used. An Apple IIe computer served as a control unit and for data acquisition.

SERR and RR spectra were recorded with a spectral slit width of $3.7 \mathrm{~cm}^{-1}$. The signals were accumulated by repetitive scanning to improve the quality of the spectra. The monochromator was calibrated against the laser line approximately each hour to avoid a spectrometer drift larger than $0.1 \mathrm{~cm}^{-1}$. Thus, the accuracy to which the spectral positions of the band maxima could be determined exclusively depends on the quality of the band-shape measurements.

SERR and RR spectra that were recorded with $0.2-\mathrm{cm}^{-1}$ step widths were analyzed by a band-fitting program using Lorentzian line shapes (Alshuth, 1985). This program is based on the methods described by Fraser and Suzuki (1970).

A standard cleaning and roughening procedure of the silver electrode was employed prior to each experiment to ensure a reproducible SERR activity (Hildebrandt et al., 1988a). Following the electrochemical roughening $\left(\sim 10 \mathrm{mC} / \mathrm{cm}^{2}\right)$, the electrode was carefully rinsed with distilled water. Then 


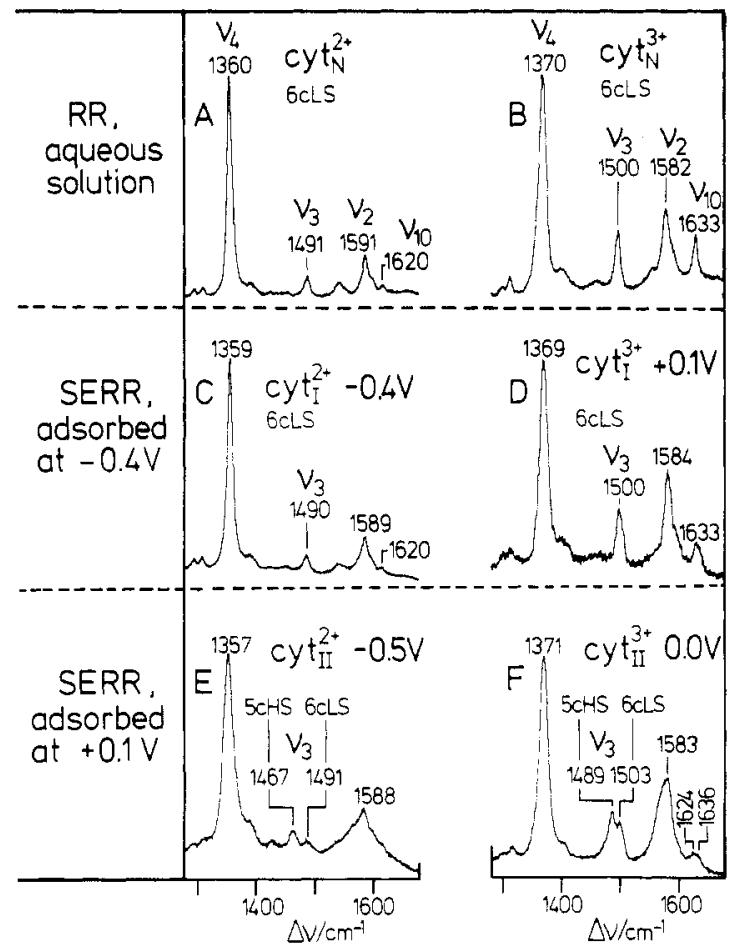

FIGURE 2: RR and SERR spectra of cyt $c$ excited at $413 \mathrm{~nm}$. (A) $\mathrm{RR}, \mathrm{cyt}_{\mathrm{N}}^{2+}$, aqueous solution. (B) $\mathrm{RR}$, cyt $\mathrm{t}_{\mathrm{N}}^{3+}$, aqueous solution. (C) SERR, cyt $t_{\mathrm{J}}^{++}$, measured at $-0.4 \mathrm{~V}$ after adsorption at $-0.4 \mathrm{~V}$. (D) SERR, cyt ${ }_{1}^{3+}$, measured at $+0.1 \mathrm{~V}$ after adsorption at $-0.4 \mathrm{~V}$. (E) SERR, cyt $\mathrm{II}^{+}$, measured at $-0.5 \mathrm{~V}$ after adsorption at $+0.1 \mathrm{~V}$. (F) SERR, cyt ti1 measured at $0.0 \mathrm{~V}$ after adsorption at $+0.1 \mathrm{~V}$. The cyt II $_{\text {II }}^{3+}$ and cyt ${ }_{i}^{2+}$ contributions are subtracted from (D) and (E), respectively (see text for details).

the buffer solution ( $0.05 \mathrm{M} \mathrm{Na}_{2} \mathrm{SO}_{4}, 0.05 \mathrm{M}$ Tris/cacodylic acid buffer at $\mathrm{pH}$ 7.0) was filled into the cell, and the solution was carefully degassed with nitrogen until at $-0.4 \mathrm{~V}$ no oxygen reduction current could be detected any more. Then the cyt $c$ solution, which was degassed separately, was added so that the final cyt $c$ concentration was $1 \times 10^{-7} \mathrm{M}$. During the measurements the solution was continuously purged with nitrogen. The $\mathrm{pH}$ of the solutions was determined with a Metrohm $632 \mathrm{pH}$ meter. Absorption spectra were measured by using a Shimadzu spectrophotometer, Model 240 .

Cyt $c$ (horse heart, type VI, Sigma) was purified according to the method of Brautigan et al. (1978). All other chemicals were of highest purity grade (Sigma, Fluka).

\section{RESULTS AND DISCUSSION}

\section{Conformational Equilibria}

Two Stable Conformational States on the Surface. The RR spectra of $\mathrm{cyt}^{2+} c$ and $\mathrm{cyt}^{3+} c$ obtained from an aqueous solution ( $\mathrm{pH} \mathrm{7.0)}$ and excited at $413 \mathrm{~nm}$ are displayed in Figure 2A,B. The spectra span the region of the oxidationand spin-state marker bands $\left(1350-1650 \mathrm{~cm}^{-1}\right)$. The frequencies of most of these bands are well correlated with the oxidation, spin, and coordination state of the iron porphyrin (Spiro, 1982; Kitagawa \& Ozaki, 1987; Parthasarathi et al., 1987). The axial ligands of cyt $c$ are provided by methionine (sulfur) and histidine (nitrogen) so that the heme iron is in the six-coordinated low spin (6cLS) configuration in both oxidation states (Dickerson \& Timkovich, 1975). This behavior is reflected, for example, by the marker bands $\nu_{4}$ at 1360 and $1370 \mathrm{~cm}^{-1}$ or $\nu_{3}$ at $1491\left(\mathrm{cyt}_{\mathrm{N}}^{2+}\right)$ and $1500 \mathrm{~cm}^{-1}\left(\mathrm{cyt}_{\mathrm{N}}^{3+}\right)$ in Figure 2A,B, where "cyt ${ }_{N}$ " denotes the native form in solution.

Adsorption of cyt $c$ at $-0.4 \mathrm{~V}$ on the Ag electrode yields a SERR spectrum (Figure $2 \mathrm{C}$ ) that is very similar to the RR spectrum of cyt $_{\mathrm{N}}^{2+}$. Under these conditions the adsorbed cyt $c$ is completely reduced; i.e., no contribution from the oxidation-state marker band $\nu_{4}$ at $\sim 1370 \mathrm{~cm}^{-1}$ could be identified. When the potential was switched from -0.4 to $+0.1 \mathrm{~V}$, a SERR spectrum (Figure 2D) was obtained that exclusively originates from the oxidized form of the adsorbed cyt $c$. Again, the vibrational pattern is very similar to the RR spectrum of cyt $_{\mathrm{N}}^{3+}$. However, at this potential, time-dependent changes in the spectrum were noted. In particular, new bands appeared at the low-frequency side of the spin-state marker bands. After about $2 \mathrm{~h}$, the spectrum was essentially the same as that in Figure $2 \mathrm{~F}$, which was immediately obtained when cyt $c$, in a separate experiment, had been adsorbed to the electrode at $+0.1 \mathrm{~V}$. The spin-state marker bands appear as doublets, for example, $\nu_{3}$ at 1489 and $1503 \mathrm{~cm}^{-1}$ or $\nu_{10}$ at 1624 and 1636 $\mathrm{cm}^{-1}$ with the low-frequency components at positions that are characteristic of the five-coordinated high-spin (5cHS) configuration (Parthasarathi et al., 1987) (Figure 2F). Obviously, under these conditions the adsorbed cyt ${ }^{3+} c$ consists of contributions from both the $6 \mathrm{cLS}$ and $5 \mathrm{cHS}$ configurations. When the potential is lowered to $-0.5 \mathrm{~V}$, the adsorbed cyt $c$ is reduced in both spin configurations as indicated by the position of the $\nu_{3}$ bands at $1467(5 \mathrm{cHS})$ and $1491 \mathrm{~cm}^{-1}(6 \mathrm{cLS})$ (Parthasarathi et al., 1987) (Figure 2E). At this potential, the spectrum changes again on the time scale of several hours until it finally approaches the vibrational pattern of the spectrum in Figure $2 \mathrm{C}$.

These results demonstrate that two conformational states of the adsorbed cyt exist depending on the electrode potential. After adsorption at negative potentials $(<-0.2 \mathrm{~V})$, a conformer is established (state $\mathrm{I} ; \mathrm{cyt}_{1}$ ) that exhibits the same electronic configuration of the heme iron (6cLS) as in the native (dissolved) form. Adsorption at positive potentials (>-0.2 V) stabilizes a second conformer (state II; cyt $_{\text {II }}$ ) that is characterized by a mixture of $5 \mathrm{cHS}$ and $6 \mathrm{cLS}$ configurations. It is necessary to note that this latter component cannot be ascribed to a residual amount of $6 \mathrm{cLS}$ cyt $c$ left from state I. As will be shown below, the spectral features as well as the redox potentials are different in the 6cLS forms of state I and state II. State II is also exclusively formed when cyt $c$ is adsorbed on the Ag electrode at open circuit or on colloidal Ag. This implies that the results presented in our previous paper (Hildebrandt \& Stockburger, 1986a) refer to the conformational state II.

It is evident from our results that only the reduced form of state $\mathrm{I}$, cyt $\mathrm{t}_{\mathrm{I}}^{2+}$, and the oxidized form of state $\mathrm{II}$, cyt $\mathrm{II}_{\mathrm{II}}^{3+}$, are stable at appropriate potentials of the electrode. SERR spectra of these species therefore can easily be obtained. Since the two other forms, cyt $t_{1}^{3+}$ and cyt $\mathrm{III}_{\text {II }}^{2+}$, at any potential slowly decay to one of the two stable species, their SERR spectra can only be obtained in pure form by subtracting the contribution of the stable forms.

Conformation of State I. The comparison of the RR spectra of cyt ${ }_{N}^{3+}$ and cyt $t_{N}^{2+}$ with the SERR spectra of cyt $_{I}^{3+}$ and cyt $_{I}^{2+}$ in the range between 150 and $1700 \mathrm{~cm}^{-1}$ reveals an excellent agreement, demonstrating that the native structure of the heme group is fully preserved on the surface in state I. Although the RR and SERR spectra exclusively display the vibrational bands of the porphyrin, they provide additional information about the protein envelope. In particular, the low-frequency region of the RR spectra of cyt $c$ in solution exhibits a unique vibrational pattern that is much more complex than in model compounds or $b$-type heme proteins. This phenomenon was ascribed to symmetry lowering of the heme in the protein matrix so that RR activity is induced to Raman-forbidden 


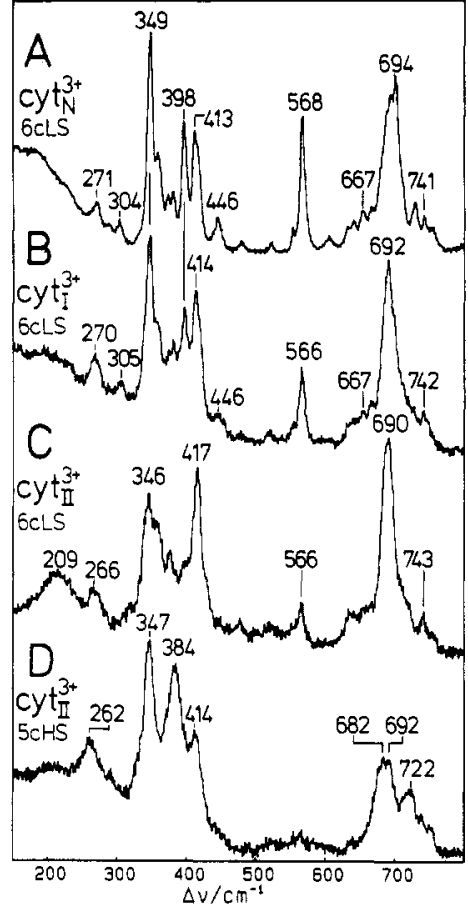

FIGURE 3: RR and SERR spectra of the oxidized cyt $c$ excited at $413 \mathrm{~nm}$. (A) RR, cyt $\mathrm{N}_{\mathrm{N}}^{3+}$, aqueous solution. (B) SERR, cyt ${ }_{1}^{3+}$. (C) SERR, cyt li $^{3+} 6 \mathrm{cLS}$. (D) SERR, cyt $\mathrm{t}_{11}^{3+} 5 \mathrm{cHS}$. (B), (C), and (D) are difference spectra (details of the subtraction procedure are given in the text).

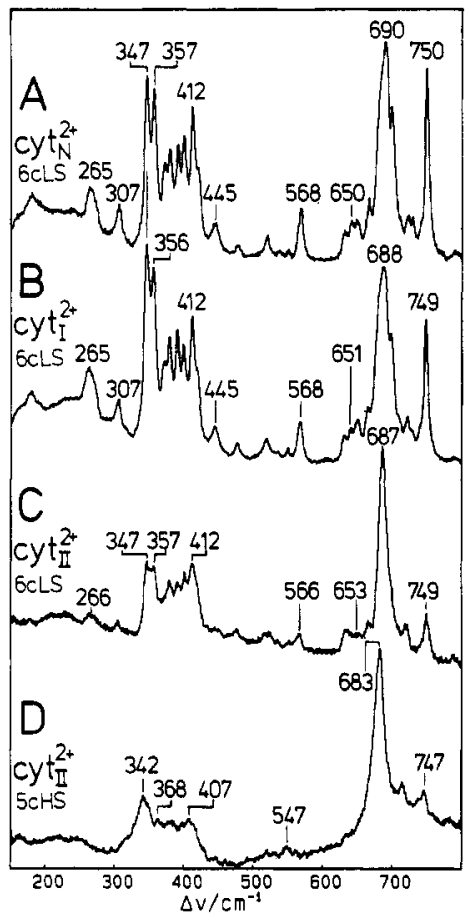

FIGURE 4: RR and SERR spectra of the reduced cyt $c$ excited at 413 nm. (A) RR, cyt ${ }^{2+}$, aqueous solution. (B) SERR, $\mathrm{cyt}_{\mathrm{I}}^{2+}$. (C) SERR, cyt $_{11}^{+2} 6 \mathrm{cLS}$. (D) SERR, cyt ${ }_{11}^{2+} 5 \mathrm{cHS}$. (C) and (D) are difference spectra (details of the subtraction procedure are given in the text).

in-plane and out-of-plane modes of the porphyrin (Valance \& Strekas, 1982). This section of the RR spectrum therefore can be regarded as a "fingerprint" for the unique structure of the heme group that is fixed by interactions with the protein envelope in $\mathrm{cyt}_{\mathrm{N}}$. The one-to-one correspondence of the $R R$ and SERR bands as shown in Figures 3A,B and 4A,B indicates that these interactions are unchanged in the adsorbed state $\mathrm{I}$, which implies that the structure of $\mathrm{cyt}_{\mathrm{I}}$ and $\mathrm{cyt}_{\mathrm{N}}$ must be

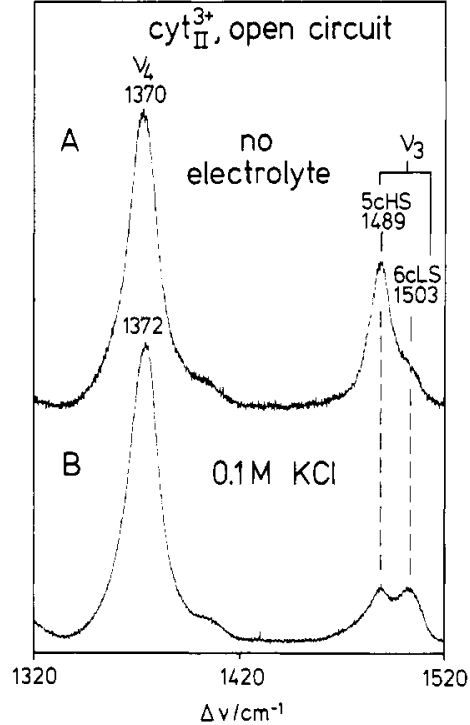

FIGURE 5: SERR spectra of cyt II $^{3+}$ at open circuit with 413-nm excitation. (A) Without electrolyte. (B) $0.1 \mathrm{M} \mathrm{KCl}$.

the same for the whole protein.

A careful inspection of the SERR and RR spectra of $\mathrm{cyt}_{\mathrm{N}}$ and $\mathrm{cyt}_{\mathrm{I}}$ reveals frequency differences for some of the bands up to $2 \mathrm{~cm}^{-1}$. While for the weak or poorly resolved bands this is within the limits of error, in the case of sharp and well-separated peaks, these differences are real. The origin for these differences may be associated with the "electrochemical Stark effect", which has recently been stressed to explain the potential dependence of the stretching frequency of CO adsorbed on electrodes (Schmidt et al., 1987). A crude estimation shows that electric field induced frequency shifts in cyt $_{\mathrm{I}}$ may indeed be of the order of $1-2 \mathrm{~cm}^{-1}$. Such an interpretation would require that the SERR frequencies vary with the electrode potential. However, the expected potential-dependent shifts of about $0.05 \mathrm{~cm}^{-1} / 0.1 \mathrm{~V}$ would be too small to be detected.

Structure and Spectra of State II. The main structural difference from state I is the partial change of the spin and coordination state. The frequencies of the spin-state marker bands are at positions that are characteristic of the $6 \mathrm{cLS}$ and $5 \mathrm{cHS}$ configurations. This implies that in state II one axial bond is broken for a part of the molecules. Most likely this is the iron-methionine bond, which is known to be easily disrupted, for example, by thermal activation (Ångström et al., 1982). In a previous paper (Hildebrandt \& Stockburger, 1986a) we had shown that in state II the $6 \mathrm{cLS}$ and $5 \mathrm{cHS}$ forms of cyt $t_{I I}^{3+}$ (and cyt $t_{I I}^{2+}$ ) are in a thermal equilibrium in which the $6 \mathrm{cLS}$ form is the thermodynamically more stable one.

The coordination equilibria in cyt $_{\mathrm{II}}$ also depend on the composition and concentration of the electrolyte in the bulk solution. Figure 5A shows the SERR spectrum of cytil at open circuit in the absence of any electrolyte. As indicated by the prominent peak at $1489 \mathrm{~cm}^{-1}\left(\nu_{3}\right)$ the $5 \mathrm{cHS}$ configuration clearly prevails. After addition of $0.1 \mathrm{M} \mathrm{KCl}$, the $6 \mathrm{cLS}$ component $\left(1503 \mathrm{~cm}^{-1}\right)$ strongly increases (Figure $5 \mathrm{~B}$ ), so that the spin-state distribution becomes essentially the same as in Figure $2 \mathrm{~F}$. Similar observations were made with perchlorate or phosphate. In contrast, addition of fluoride $(0.1 \mathrm{M} \mathrm{NaF})$ does not change the SERR spectrum in Figure 5A. These electrolyte-induced changes of the spin-state equilibrium are fully reversible and were also found for $\mathrm{F}^{-} / \mathrm{SO}_{4}{ }^{2-}$ exchange in cyt $t_{\mathrm{II}}^{2+}$. Such effects were used to obtain "pure" spectra of the $6 \mathrm{cLS}$ and $5 \mathrm{cHS}$ configurations in state II by subtracting 
the SERR spectra measured in the presence of $\mathrm{F}^{-}$or $\mathrm{SO}_{4}{ }^{2-}$ in an adequate way. Spectra of this type are shown in Figures $3 C, D$ and $4 C, D$ for the fingerprint region.

For a comparison of the spectra in Figures 3 and 4 one has to consider that the Soret band of HS iron porphyrins is blue-shifted compared with the related LS components [see, for example, Rein et al. (1984)]. For totally symmetric vibrations $\left(A_{1 g}\right)$, which exhibit a sharp Raman excitation profile in the Soret region (Remba et al., 1979; Spiro, 1983), one therefore would expect relative intensity changes if the excitation line is kept at a fixed position $(413 \mathrm{~nm})$. As an example for such a resonance effect we mention the $\mathrm{A}_{1 \mathrm{~g}}$ mode $\nu_{7}$, which in the spectrum of cyt ${ }_{11}^{3+} 6 \mathrm{cLS}$ (Figure $4 \mathrm{C}$ ) lies at $690 \mathrm{~cm}^{-1}$ and nearly vanishes for the $5 \mathrm{cHS}$ configuration (Figure 4D). However, most of the vibrations in the fingerprint region are non totally symmetric with a flat excitation profile and therefore do not exhibit such pronounced resonance effects.

$5 \mathrm{cHS}$ Configuration in State II. In this configuration that results from the rupture of the $\mathrm{Fe}-\mathrm{S}$ (Met) bond the iron atom has moved out-of-plane and the porphyrin ring system has expanded. This is reflected by the characteristic spin-state marker bands (Spiro, 1983; Parthasarati et al., 1987) as seen in the spectra of Figure 2. The assignment of these modes for state II has been discussed by Hildebrandt and Stockburger (1986a).

Also in the fingerprint region (Figures 3D and 4D) the spectra of 5cHS forms are clearly different from those of the $6 \mathrm{cLS}$ configurations, reflecting the structural rearrangement of the heme binding pocket that accompanies the dissociation of the Met ligand. For example, the manifold of sharp bands between 300 and $450 \mathrm{~cm}^{-1}$ in the $6 \mathrm{cLS}$ configurations of cyt ${ }^{3+}$ are replaced by three broad bands in the SERR spectrum of $\mathrm{cyt}_{\text {II }}^{3+} 5 \mathrm{cHS}$, which in turn is closely related to the RR spectra of iron porphyrin compounds in aqueous solution [see, for example, Choi and Spiro (1983)]. These findings indicate that in the $5 \mathrm{cHS}$ form the steric constraints by the protein envelope are largely removed. A similar conclusion can be reached from the comparison of the 5cHS and 6cLS forms of $\mathrm{cyt}_{11}^{2+}$ (Figure $4 C, D)$.

6cLS Configuration in States I and II. Striking similarities are noted between the SERR spectra in the fingerprint region of the $6 \mathrm{cLS}$ forms in both states (Figures $3 \mathrm{~B}, \mathrm{C}$ and $4 \mathrm{~B}, \mathrm{C}$ ). Most of the bands that are observed for state I are also found in the $6 \mathrm{cLS}$ forms of state II with frequency shifts of less than $4 \mathrm{~cm}^{-1}$. Also, the relative intensities are quite similar with the exception of the band at $687 \mathrm{~cm}^{-1}\left(\nu_{7}\right)$, which in state II is more intense than in state I (Figure 3B,C). These findings suggest that the two $6 \mathrm{cLS}$ forms do not differ strongly in structure.

On the other hand, there must be some structural difference between the two $6 \mathrm{cLS}$ forms that can account for the ability of state II to form thermal coordination equilibria with significant populations of the $5 \mathrm{cHS}$ configuration even at room temperature. As pointed out by Ångström et al. (1982), the weakening and subsequent rupture of the Fe-methionine bond is accompanied by an opening of the heme crevice. Apparently, this structural rearrangement of the heme pocket, which is already realized in the $6 \mathrm{cLS}$ form of state II, gives rise only to minor changes in the SERR spectra as long as the $6 \mathrm{cLS}$ configuration is maintained. Interesting features are, for example, the bands 446 and $305 \mathrm{~cm}^{-1}$ of cyt ${ }_{1}^{3+}$ (Figure 4B) which are respectively missing and shifted to $318 \mathrm{~cm}^{-1}$ in cyt ${ }_{1 I}^{3+}$ 6cLS (Figure $4 \mathrm{C}$ ). Thus, it may be that these bands, which are also missing in the $5 \mathrm{cHS}$ form of $\mathrm{cyt}_{\mathrm{II}}$ (Figure 4D), are characteristic markers for the structural integrity of the heme binding pocket in cyt $c$. Also, the frequency upshifts of the

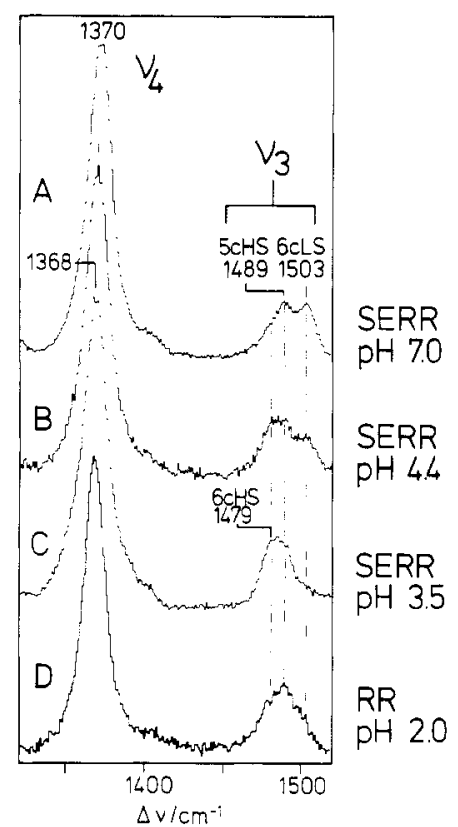

FIGURE 6: SERR spectra of cyt $\mathrm{tII}_{\mathrm{II}}^{3+}(0.0 \mathrm{~V})$ at different $\mathrm{pH}$ values (A-C) compared with the RR spectrum of cyt $\mathrm{N}_{\mathrm{N}}^{3+}$ in aqueous solution at $\mathrm{pH} 2.0$ (excitation wavelength $=413 \mathrm{~nm}$ ).

spin-state marker bands by up to $\sim 3 \mathrm{~cm}^{-1}\left(\nu_{3}, \nu_{10}\right.$; Figure 2), which correspond to a contraction of the heme core by about $0.01 \AA$ (Parthasarathi et al., 1987), may reflect the structural changes of the heme crevice in state II. In spite of these differences, the great similarities between the SERR spectra of the LS forms of state I and state II apparently rule out major structural changes of the overall protein structure in state II. Further support for this conclusion will be presented in the following section.

Proton-Induced Conformational Changes in State II. The dissolved cyt ${ }^{3+} c$ is involved in several $\mathrm{pH}$-dependent conformational equilibria (Theorell \& Åkesson, 1941; Dickerson \& Timkovich, 1975). The reversible conformational transition at low $\mathrm{pH}\left(\mathrm{p} K_{\mathrm{a}}=2.5\right)$ includes a rearrangement of the polypeptide backbone leading to a partial replacement of the native axial ligands, presumably by $\mathrm{H}_{2} \mathrm{O}$ molecules. Under these conditions the heme iron exists in a mixture of $6 \mathrm{cHS}$, $5 \mathrm{cHS}$, and $6 \mathrm{cLS}$ configurations as it is reflected by three bands of the $\nu_{3}$ mode at $1481.0,1491.5$, and $1502.6 \mathrm{~cm}^{-1}$ (P. Hildebrandt, unpublished results). This conformational transition also reversibly takes place in the adsorbed cyt $\mathrm{t}_{\mathrm{II}}^{3+}$, although at a different $\mathrm{p} K_{\mathrm{a}}$. Figure 6 shows the SERR spectra of cyt ${ }_{\text {II }}^{3+}$ at different $\mathrm{pH}$ values. The $1479-\mathrm{cm}^{-1}$ band of the $6 \mathrm{cHS}$ configuration, which can already be detected as a shoulder at $\mathrm{pH} 7.0$, considerably increases when the $\mathrm{pH}$ is lowered (Figure $6 \mathrm{~A}-\mathrm{C})$. Below $\mathrm{pH} 3.5$ no further changes are noted in the SERR spectra. This suggests that the apparent $\mathrm{p} K_{\mathrm{a}}$ of cyt $\mathrm{III}^{3+}$ is about 2 units higher than for $\mathrm{cyt}_{\mathrm{N}}^{3+}$. This may be due to the effect of the electric field in the electrical double layer on the ionic equilibria of the amino acid side chains of the adsorbed cyt $t_{I I}^{3+}$ (Neumann, 1981). The SERR spectrum of the acid form of cyt $\mathrm{II}_{I 1}^{3+}$ is closely related to the RR spectrum of the acid form in solution (Figure 6D).

The similarities of the proton-induced conformational transitions in cyt $\mathrm{N}_{\mathrm{N}}^{3+}$ and cyt $\mathrm{t}_{\mathrm{II}}^{3+}$ unambiguously demonstrate that the overall protein structure must be largely intact in state II of the adsorbed species (i.e., similar to that in the dissolved cyt $c$ ) and that binding to the $\mathrm{Ag}$ electrode does not restrict the flexibility of the protein significantly. ${ }^{2}$ 


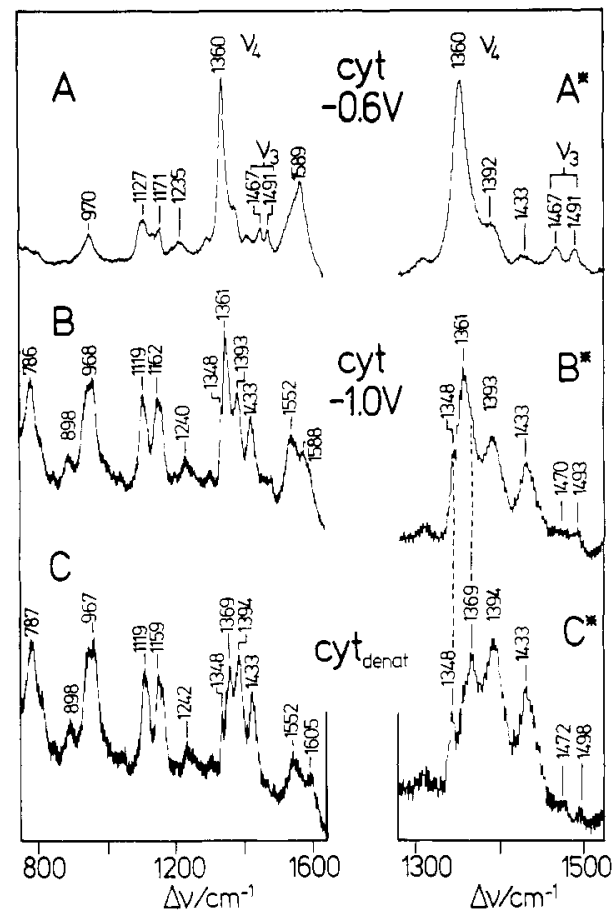

FIGURE 7: SERR spectra of cyt $c$ excited with $457 \mathrm{~nm}$. (A) $-0.6 \mathrm{~V}$. (B) $-1.0 \mathrm{~V}$. Spectrum $\mathrm{C}$ is obtained by subtracting the cyt $\mathrm{II}_{\mathrm{II}}^{2+}$ content from spectrum B. The spectra marked by asterisks show the $1280-$ $1520-\mathrm{cm}^{-1}$ region on an extended scale.

Denaturation of the Adsorbed cyt $c$. Figure 7A shows the SERR spectrum of cyt $\mathrm{II}_{\mathrm{II}}^{2+}$ at $-0.6 \mathrm{~V}$ excited at $457 \mathrm{~nm}$. The spectral features are very similar to those obtained with 413-nm excitation (Figure 2E). When the potential is lowered, the $1360-\mathrm{cm}^{-1}$ band strongly decreases while several broad peaks in the region between 750 and $1200 \mathrm{~cm}^{-1}$ grow in (Figure 7B). These spectral changes are irreversible; i.e., switching the potential back to $-0.6 \mathrm{~V}$ does not restore the original spectrum. This implies that the SERR spectrum in Figure $7 \mathrm{~B}$ reflects to a considerable degree an irreversibly denatured form of the adsorbed cyt (cyt denat). To obtain a pure SERR spectrum of cyt denat, we have subtracted the contribution of cyt ${ }_{\text {II }}^{2+}$ in Figure 7B using the $1360-\mathrm{cm}^{-1}$ band as a reference. The difference spectrum (Figure $7 \mathrm{C}$ ) bears only a weak resemblance to the SERR spectra of cyt $_{\text {I }}$ or cyt ${ }_{\text {II }}$ or even with the RR spectra of iron porphyrin compounds in general. For example, the region between 1300 and $1500 \mathrm{~cm}^{-1}$ (Figure $7 \mathrm{C}^{*}$ ) is significantly more complex than in cyt $\mathrm{II}_{\mathrm{II}}^{2+}$ (Figure $7 \mathrm{~A}^{*}$ ), so that it is difficult to identify the marker bands $\nu_{4}$ and $\nu_{3}$. The underlying structural changes are probably associated with a complete unfolding of the protein. It is likely that the denatured cyt $c$ is not homogeneous but exists in different conformational states. This interpretation would explain the broad and poorly resolved structures of the bands in particular between 700 and $1200 \mathrm{~cm}^{-1}$ (inhomogeneous broadening). It is also interesting to note that the intensities of the SERR bands of cyt denat relative to cyt $\mathrm{t}_{1}^{2+}$ or cyt $\mathrm{t}_{\mathrm{II}}^{2+}$ are weaker with 413-nm than with $456-\mathrm{nm}$ excitation, pointing to a red shift of the Soret transition.

${ }^{2}$ A similar conclusion is obtained from the experiments of Vanhecke and Heremans (1988). These authors have studied the reversible alkaline transition of cyt ${ }^{3+}$ at $\mathrm{pH} \sim 10$ that leads to the replacement of the methionine ligand by a histidine or a lysine (Dickerson \& Timkovich, 1975). They have observed this transition also for cyt $^{3+}$ adsorbed on colloidal Ag, where, as we have shown, state II prevails. Furthermore, the spectra reported by these authors clearly demonstrate that the $6 \mathrm{cLS}$ forms of cyt ${ }_{11}^{3+}$ at $\mathrm{pH} 7.0$ and $\mathrm{pH} 10.6$ are structurally different.

\section{Redox Equilibria}

Quantitative Analysis of the Redox Processes of the Adsorbed cyt $c$. Since the various conformational states of the adsorbed cyt $c$ can be distinguished by the positions of the spinand oxidation-state marker bands $\nu_{4}$ and $\nu_{3}$, the analysis of the SERR spectra measured at different potentials can provide a quantitative description of the potential-dependent processes of the adsorbed species. From experiments as described in Figure 2 it is expected that the redox potential of state I lies at $\sim 0.0 \mathrm{~V}$, while that of state II is close to $-0.35 \mathrm{~V}$. To analyze the redox processes of the two states independently, we varied the potential between +0.075 and $-0.075 \mathrm{~V}$ (range A) and between -0.3 and $-0.45 \mathrm{~V}$ (range B) in steps of $25 \mathrm{mV}$. Within these ranges the SERR spectra $\left(1320-1520 \mathrm{~cm}^{-1}\right)$ were measured to a high accuracy $\left(0.2-\mathrm{cm}^{-1}\right.$ step width). The pure states I and II were prepared by adsorbing cyt $c$ on the $\mathrm{Ag}$ electrode at $-0.4 \mathrm{~V}$ (state I) or $+0.1 \mathrm{~V}$ (state II) prior to switching the potential to the desired value in range $A$ or range B.

Unfortunately, as we already discussed, states I and II are not stable in the potential ranges $A$ and $B$ but are slowly converted into each other. Thus, it was necessary to keep this effect as small as possible. In preliminary experiments it was found that local heating of the sample by the exciting laser beam accelerated the conformational transitions. This implies that long-time measurements with high laser powers inevitably reduced the content of the redox couple under consideration. On the other hand, the prolonged accumulation of the SERR signals is a prerequisite for obtaining the high spectral quality necessary for the band-fitting analysis. Thus, we made a compromise. All SERR spectra were recorded with an irradiance of $4.0 \mathrm{~W} / \mathrm{cm}^{2}$ at the sample and under continuous rotation of the electrode. The time of the individual measurements was limited to $30 \mathrm{~min}$ (range A) and $45 \mathrm{~min}$ (range B), and then the sample was renewed. Under these conditions the electron-transfer reactions and the spin transitions (in state II) but not the conformational transitions (between states I and II) are in thermodynamic equilibrium. This procedure was repeated five times for each potential value, and the five spectra obtained at each potential were added. It should be mentioned that the individual spectra of the same potential were identical, demonstrating the reproducibility of this procedure.

The SERR spectra in ranges A and B include contributions of various states of cyt $c$. It is evident that a band-fitting analysis can only provide physically meaningful results when the spectral parameters of $\nu_{4}$ and $\nu_{3}$ are known for the individual species. These parameters are given by the frequencies, the half-widths $\Delta \nu_{4}$ and $\Delta \nu_{3}$, and the intensity ratio $R$ of the two bands. These quantities were determined from the pure spectra of the individual species that were either measured directly ( $\mathrm{cyt}_{\mathrm{II}}^{2+}$ at $-0.4 \mathrm{~V}$ ) or obtained by difference procedures. For example, measuring the SERR spectra of cyt $_{\text {II }}$ in the presence of different electrolytes gave different ratios of the $6 \mathrm{cLS}$ and $5 \mathrm{cHS}$ configurations (see Figure 5). Subtracting these spectra from each other, it was possible to obtain relatively pure spectra of $\mathrm{cyt}_{\text {II }}^{3+} 6 \mathrm{cLS}$ and $\mathrm{cyt}_{\mathrm{II}}^{3+} 5 \mathrm{cHS}$ at $0.0 \mathrm{~V}$ and of cyt $\mathrm{II}_{\mathrm{II}}^{2+} 6 \mathrm{cLS}$ and $\mathrm{cyt}_{\mathrm{II}}^{2+} 5 \mathrm{cHS}$ at $-0.5 \mathrm{~V}$ that could be analyzed separately. In a similar way, difference spectra could be derived from the SERR spectra measured at -0.7 and -0.5 $\mathrm{V}$, which mainly reflect cyt $\mathrm{t}_{\text {denat }}^{3+}$ and cyt $\mathrm{t}_{\text {denat }}^{2+}$. The spectrum of $\mathrm{cyt}_{\mathrm{II}}^{3+}$ (acid) 6cHS was obtained by subtracting the SERR spectrum of cyt $\mathrm{II}^{3+}$ at $\mathrm{pH} 7.0$ from the one measured at $\mathrm{pH} 2.0$ $(0.0 \mathrm{~V})$. 
Table I: Spectral Parameters ${ }^{a}$ of the Various Species of the Adsorbed and Dissolved cyt $c$

\begin{tabular}{|c|c|c|c|c|c|c|}
\hline species & $\left(\begin{array}{c}v_{4} \\
\left.\mathrm{~cm}^{-1}\right)\end{array}\right.$ & $\begin{array}{c}\Delta \nu_{4} \\
\left(\mathrm{~cm}^{-1}\right)\end{array}$ & $\left(\begin{array}{c}v_{3} \\
\left(\mathrm{~cm}^{-1}\right)\end{array}\right.$ & $\begin{array}{c}\Delta \nu_{3} \\
\left(\mathrm{~cm}^{-1}\right)\end{array}$ & $R^{b}$ & $\begin{array}{l}\Delta R \\
(\%)\end{array}$ \\
\hline $\operatorname{cyt}_{\mathrm{N}}^{2+} 6 \mathrm{cLS}$ & 360,4 & 9.8 & 1490.5 & 12.0 & 11.8 & \\
\hline cyt ${ }_{N}^{3+} 6 \mathrm{cLS}$ & 1370.1 & 15.1 & 1500.4 & 11.1 & 3.7 & \\
\hline $\mathrm{cyt}^{2+} 6 \mathrm{cLS}$ & 1358.8 & 9.9 & 1489.8 & 12.3 & 12.0 & 7.1 \\
\hline $\mathrm{cyt}_{1}^{3+} 6 \mathrm{cLS}$ & 1369.0 & 12.0 & 1499.5 & 11.4 & 3.1 & 12.1 \\
\hline cyt ${ }^{2+} 6 \mathrm{cLS}$ & 1362.5 & 13.3 & 1491.1 & 12.1 & 10.2 & 7.7 \\
\hline cyt $\mathrm{II}^{3+} 6 \mathrm{cLS}$ & 1373.6 & 13.7 & 1503.1 & 11.6 & 4.1 & 10.7 \\
\hline $\mathrm{cyt}_{11}^{2+} 5 \mathrm{cHS}$ & 135 & 14.4 & 1467.3 & 14.4 & 7.2 & 2.3 \\
\hline $\mathrm{cyt}_{11}^{3+} 5 \mathrm{cHS}$ & 1367.8 & 11.8 & 1488.4 & 12.5 & 1.45 & 8.9 \\
\hline $\mathrm{cyt}_{\text {II }}^{3+}$ (acid) $6 \mathrm{cHS}$ & 1365.4 & 13.3 & 1478.7 & 16.1 & 6.75 & 9.9 \\
\hline & 1348.8 & 13.5 & 1471.5 & 14.5 & 12.6 & 9.4 \\
\hline cytdenat & 11369.4 & 12.9 & 1497.8 & 11.3 & 9.5 & 14.1 \\
\hline
\end{tabular}

${ }^{a}$ The standard deviation for frequencies $\left(\nu_{i}\right)$ and half-widths $\left(\Delta \nu_{i}\right)$ was about $\pm 0.2 \mathrm{~cm}^{-1}$. The standard deviations for $R(\Delta R)$ are listed in the table. ${ }^{b} R=I\left(\nu_{4}\right) / I\left(\nu_{3}\right)$.

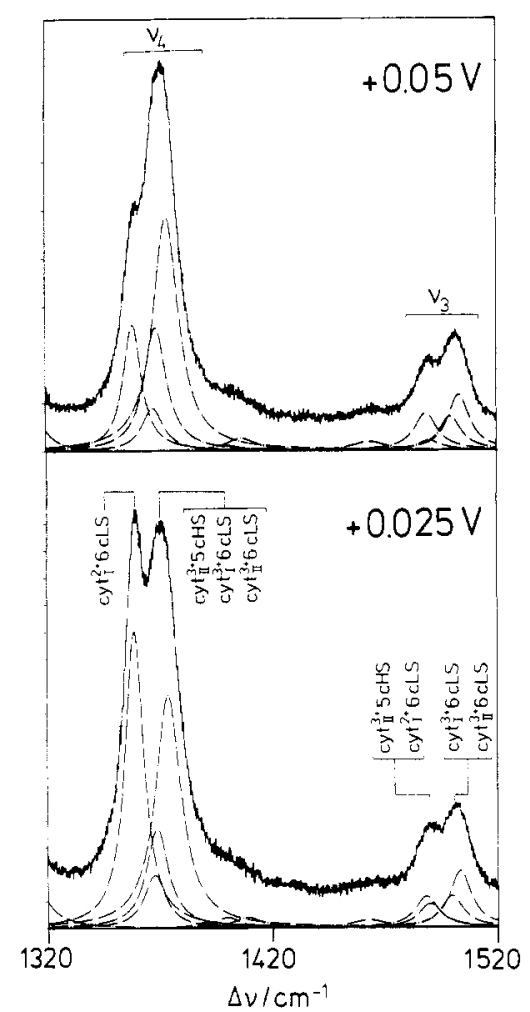

FIGURE 8: Fitted SERR spectra of cyt $c$ excited at $413 \mathrm{~nm}$ in the potential range A. The contributions of cyt $\mathrm{cH}^{3+}$ (acid) $6 \mathrm{cHS}$ are subtracted. The dotted lines are the calculated Lorentz profiles.

Thus, an initial set of spectral parameters was available that were iteratively improved in the band-fitting analysis of the SERR spectra in the potential ranges $A$ and $B$ until in all cases the standard deviations for the frequencies and half-widths did not exceed $\pm 0.2 \mathrm{~cm}^{-1}$ and the intensity ratios were constant within $\pm 10 \%$. These spectral parameters are listed in Table I. The underlying assumption of this approach is that frequencies, half-widths, and relative intensities are potential independent. Indeed, a careful inspection of the SERR spectra of the pure cyt $\mathrm{I}_{\mathrm{I}}^{2+} 6 \mathrm{cLS}$ between -0.2 and $-0.5 \mathrm{~V}$ revealed that the spectral parameters remained constant within the experimental accuracy $\left( \pm 0.2 \mathrm{~cm}^{-1}\right.$ for $\nu_{\mathrm{i}}$ and $\Delta \nu_{\mathrm{i}}$ and $3 \%$ for $\left.R\right)$. Figures 8 and 9 display some of the spectra that were analyzed in this way.

Evaluation of the Relative SERR Intensities. It should be mentioned that despite the high number of different components the computer analysis provided unambiguous results, which is due to the introduction of several constraints to the procedure. The frequencies and half-widths were allowed to

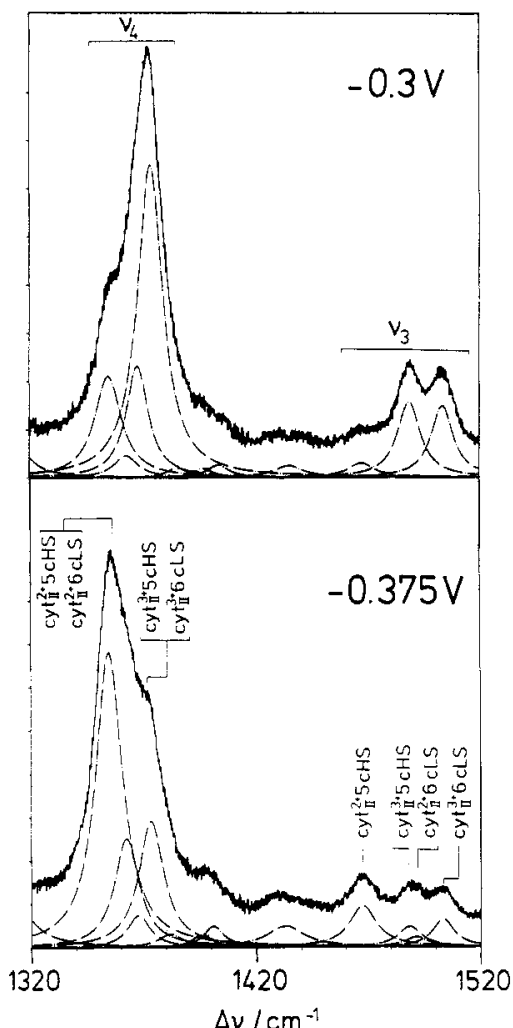

FIGURE 9: Fitted SERR spectra of cyt $c$ excited at $413 \mathrm{~nm}$ in the potential range $\mathrm{B}$. The contributions of $\mathrm{cyt}_{\mathrm{II}}^{3+}$ (acid) $6 \mathrm{cHS}$, cyt $\mathrm{F}_{\mathrm{I}}^{2+} 6 \mathrm{cLS}$, and the denatured forms are subtracted for the sake of clarity of the presentation. The dotted lines are the calculated Lorentz profiles.

vary only in a limited range so that the suppression of weak bands by adjacent strong bands could be avoided. Additionally, for each conformer the relative intensities of $\nu_{4}$ and $\nu_{3}$, which appear in well-separated spectral regions, were related to each other by a constant factor $R$ so that the number of degrees of freedom in the fitting routine was further reduced. Under such conditions the relative intensities calculated in different runs were highly reproducible. Starting with the same set of spectral parameters but with different initial intensities led to deviations of the intensities for most of the bands of less than $3 \%$. Only in the case of very weak bands, for example, $\nu_{4}$ and $\nu_{3}$ of $\mathrm{cyt}_{\mathrm{II}}^{2+} 6 \mathrm{cLS}$ at $-0.3 \mathrm{~V}$ or cyt $\mathrm{I}_{\mathrm{I}}^{3+} 6 \mathrm{cLS}$ at $-0.075 \mathrm{~V}$, did the deviations exceed $10 \%$.

In Table II the relative intensities obtained from the fitting procedure are listed for all cyt $c$ species in both potential ranges. The data are average values $\left(I_{\mathrm{av}}\right)$ of the $\nu_{4}$ and $\nu_{3}$ band intensities according to

$$
I_{\mathrm{av}}=\left[I\left(\nu_{4}\right)+R I\left(\nu_{3}\right)\right] / 2
$$

Finally we note that except for $\nu_{4}$ and $\nu_{3}$ the analyzed SERR spectra also include weak bands originating from other modes between 1390 and $1420 \mathrm{~cm}^{-1}$. Although these modes appear at slightly different frequencies in the various cyt $c$ species, they were taken into account by single Lorentzian lines in the band-fitting analysis.

The relative intensities $I_{i}$ are proportional to the relative concentrations $C_{\mathrm{i}}$ of the individual species according to

$$
C_{\mathrm{i}}=f_{i} I_{i}
$$

The determination of the proportionality factors $f_{i}$ (Table II) is described in the Appendix.

The implicit assumptions of eq 2 are that the measured intensities exclusively result from the adsorbed molecules and that the surface enhancement of the Raman scattering is the same for all adsorbed molecules of a given species, i.e., the 
Table II: Relative SERR Intensities (in Arbitrary Units) of the Various Cytochrome Species for 413-nm Excitation As Derived from the Band-Fitting Analysis at Different Potentials ${ }^{a}$

\begin{tabular}{|c|c|c|c|c|c|c|c|c|c|}
\hline \multirow[b]{2}{*}{$\begin{array}{c}E \\
(\mathrm{~V}, \text { vs SCE})\end{array}$} & \multirow{2}{*}{$\begin{array}{c}\mathrm{cyt}_{\mathrm{I}}^{2+} \\
6 \mathrm{cLS} \\
(0.39)^{b}\end{array}$} & \multirow{2}{*}{$\begin{array}{c}\mathrm{cyt}_{1}^{3+} \\
6 \mathrm{cLS} \\
(1.25)\end{array}$} & \multirow{2}{*}{$\begin{array}{c}\text { cyt }_{\text {II }}^{2+} \\
6 \mathrm{cLS} \\
(0.54)\end{array}$} & \multirow{2}{*}{$\begin{array}{c}\text { cyt }_{\mathrm{II}}^{3+} \\
6 \mathrm{cLS} \\
(2.40)\end{array}$} & \multirow{2}{*}{$\begin{array}{c}\text { cytti1 }_{11}^{2+} \\
5 \mathrm{cHS} \\
(4.1)\end{array}$} & \multirow{2}{*}{$\begin{array}{c}\mathrm{cyt}_{\mathrm{II}}^{3+} \\
5 \mathrm{cHS} \\
(4.8)\end{array}$} & \multirow[b]{2}{*}{$\begin{array}{l}\operatorname{cyt}_{11}^{3+} \text { (acid) } \\
6 \mathrm{cHS}(1.5)\end{array}$} & \multicolumn{2}{|c|}{ cyt $_{\text {denat }}$} \\
\hline & & & & & & & & $\begin{array}{c}1349 \mathrm{~cm}^{-1} \\
(2.1)\end{array}$ & $\begin{array}{c}1369 \mathrm{~cm}^{-1} \\
(1.0)\end{array}$ \\
\hline+0.075 & 2677 & 5471 & & 12631 & & 2695 & 5957 & & \\
\hline+0.050 & 7147 & 5868 & & 13028 & & 2945 & 4949 & & \\
\hline+0.025 & 16105 & 5155 & & 12546 & & 2492 & 4078 & & \\
\hline 0.0 & 21581 & 3302 & & 12239 & & 2584 & 6074 & & \\
\hline-0.025 & 36578 & 2603 & & 12345 & & 1496 & 5459 & & \\
\hline-0.050 & 50851 & 1210 & & 10686 & & 1448 & 6029 & & \\
\hline-0.075 & 74003 & 620 & & 10554 & & 785 & 5328 & & \\
\hline-0.300 & 8846 & & 748 & 10710 & 3458 & 4007 & 4894 & 2263 & 5088 \\
\hline-0.325 & 14812 & & 1699 & 8464 & 5447 & 2530 & 5331 & 3194 & 6404 \\
\hline-0.350 & 15058 & & 2983 & 6625 & 9527 & 2109 & 3965 & 4376 & 3748 \\
\hline-0.375 & 17008 & & 4305 & 4918 & 12677 & 1362 & 2777 & 5092 & 3525 \\
\hline-0.400 & 12061 & & 4761 & 2493 & 16285 & 653 & 1237 & 6116 & 3388 \\
\hline-0.425 & 9812 & & 5056 & 1038 & 20718 & 315 & & 6965 & 3400 \\
\hline-0.45 & 11830 & & 5205 & 491 & 21550 & 95 & & 8587 & 3775 \\
\hline
\end{tabular}

${ }^{a}$ The intensity values are the average determined from $\nu_{4}$ and $\nu_{3}$ (see eq 1). ${ }^{b}$ The $f_{i}$ values $\left(\times 10^{5}\right)$ as defined according to eq 2 are given in parentheses (see Appendix).

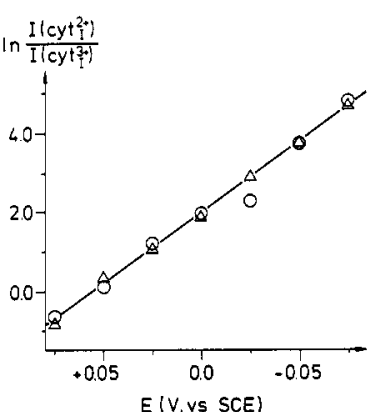

FIGURE 10: Nernstian plot of the intensity ratio of cyt $_{1}^{2+}$ and cyt $_{1}^{3+}$ versus the potential. The triangles and circles are the values derived from the $\nu_{4}$ and $\nu_{3}$ band intensities, respectively. The values from $\nu_{3}$ are multiplied by $R$ according to eq 1 .

same for all adsorption sites. Measurements of the concentration dependence of the SERR intensity of cyt $\mathrm{II}_{\mathrm{II}}^{3+}$ adsorbed on $\mathrm{Ag} \mathrm{sol}$ have demonstrated that these assumptions are fully justified (Hildebrandt \& Stockburger, 1986a).

Redox Equilibrium of State $I$. In the thermodynamic equilibrium a redox couple must obey the Nernst equation

$$
E=E_{0}-\frac{R T}{n F} \ln \frac{C_{\mathrm{red}}}{C_{\mathrm{ox}}}=E_{0}-\frac{R T}{n F} \ln \frac{I_{\mathrm{red}} f_{\mathrm{red}}}{I_{\mathrm{ox}} f_{\mathrm{ox}}}
$$

where $E_{0}$ is the redox potential and $n$ the number of transferred electrons. $R$ and $F$ denote the gas and the Faraday constant, respectively, and $T$ and $E$ are the temperature and the electrode potential, respectively.

First we want to consider the redox reactions of state I. In Figure 10 the intensity ratios of $\mathrm{cyt}_{\mathrm{I}}^{2+} 6 \mathrm{cLS}$ and cyt $\mathrm{I}_{\mathrm{I}}^{3+} 6 \mathrm{cLS}$ derived from $\nu_{4}$ (triangles) and $\nu_{3}$ bands (circles) are plotted versus the potential. The data follow a straight line with a slope corresponding to a value of 0.95 for $n$, which reflects an ideal Nernstian behavior for a one-to-one redox couple. By use of the $f_{i}$ values in Table II eq 3 yields a redox potential of $+0.02 \mathrm{~V}$. This value is close to the redox potential of cyt $c$ in solution (+0.01 V) (Dickerson \& Timkovich, 1975), which is not surprising in view of the preservation of the native structure in state $I$.

Redox Equilibria of State II. The situation is more complicated in state II. There are two possible pathways of electron transfer for each redox couple, one under conservation of the coordination configuration and one in which this state is changed (Figure 11). On the basis of experimental results, we cannot distinguish between both types of pathways.

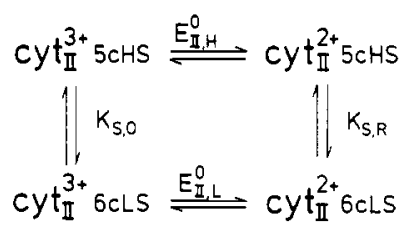

FIGURE 11: Reaction scheme of the redox process of $\mathrm{cyt}_{\mathrm{II}}$. $E_{\mathrm{II}, \mathrm{H}}^{0}$ and $E_{\text {IIL }}^{0}$ denote the redox potentials of the $5 \mathrm{cHS}$ and the $6 \mathrm{cLS}$ redox couples, respectively. $K_{\mathrm{S}, \mathrm{O}}$ and $K_{\mathrm{S}, \mathrm{R}}$ are the equilibrium constants for coordination equilibria of cyt $\mathrm{III}_{\mathrm{II}}^{+9}$ and $\mathrm{cyt}_{\mathrm{II}}^{2+}$, respectively.

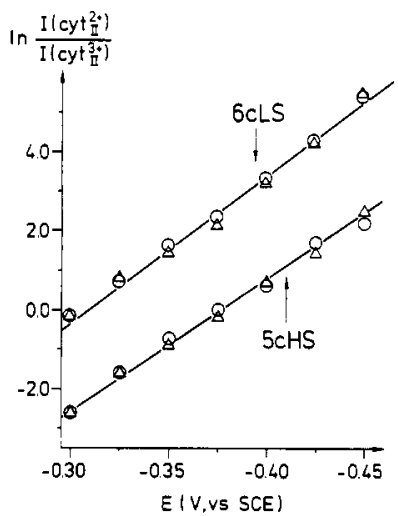

FIGURE 12: Nernstian plots of the intensity ratios of the 6cLS (upper curve) and $5 \mathrm{cHS}$ configurations (lower curve) of cyt $\mathrm{tII}_{\text {II }}^{+}$and cyt $\mathrm{t}_{I I}^{3+}$ versus the potential. The triangles and circles are the values derived from the $\nu_{4}$ and $\nu_{3}$ band intensities, respectively. The values from $\nu_{3}$ are multiplied by $R$ according to eq 1 .

However, it must be taken into account that a concomitant change of the coordination state would significantly reduce the probability of the electron transfer due to the much higher reorganization energy. Therefore, we will interpret our data exclusively on the basis of the reaction scheme in Figure 11.

In analogy to state $I$, we have plotted the relative intensities of $\mathrm{cyt}_{\mathrm{II}}^{2+} 6 \mathrm{cLS}$ and $\mathrm{cyt}_{\mathrm{II}}^{3+} 6 \mathrm{cLS}$ and of the respective $5 \mathrm{cHS}$ forms versus the potential (Figure 12). The data follow the Nernst eq 3 with values for $n$ of 0.94 and 0.86 and redox potentials of -0.31 and $-0.41 \mathrm{~V}$ for the $5 \mathrm{cHS}$ and $6 \mathrm{cLS}$ configurations, respectively.

Now we want to discuss the molecular basis for the significantly different magnitudes of the redox potentials in states I and II. The correlation between the redox potential and structural parameters of heme $\mathrm{C}$ proteins had extensively been addressed in numerous experimental and theoretical studies [see Cusanovich et al. (1988) for a detailed discussion]. The 
factors that had been found to control the redox potential are the solvent exposure of the heme and the hydrophobicity of its environment, the three-dimensional structure of the protein, the electronic configuration of the heme iron (spin state), and the type of axial ligands. Let us first consider the $6 \mathrm{cLS}$ redox couples of states I and II. Since the spin and coordination states are the same, the potential difference of $0.43 \mathrm{~V}$ between the states must exclusively result from structural and dielectric changes of the heme surroundings. On the basis of studies with different heme proteins and model compounds, Kassner (1972) had shown that the redox potential decreases with decreasing hydrophobicity of the porphyrin environment. This may probably give the main contribution to the large negative shift of the redox potential we have found for $\mathrm{cyt}_{\mathrm{II}} 6 \mathrm{cLS}$. The distortion of the closed structure of the heme crevice in this species may lead to an increase of the local dielectric constant in the immediate heme environment. However, this is presumably not the only reason for the downshift of $E_{0}$ since even for a cyt $c$ model compound with a largely solvent exposed porphyrin (heme C-octapeptide-methionine complex, 6cLS) the redox potential is not lower than $-0.3 \mathrm{~V}$ (Kassner, 1972).

Another parameter that may affect the redox potential had been stressed by Korszun et al. (1982). The authors pointed out that repulsive interactions of the hydrogen atoms of the axially bound histidine with the nonbonding $\mathrm{d}_{x z}$ and $\mathrm{d}_{y z}$ orbitals of the iron can raise the corresponding energy levels so that $E_{0}$ shifts to negative values. On the basis of crystallographic data it was concluded that these interactions are small in cyt $\mathrm{N}_{\mathrm{N}}$ but maximized in so-called tailed porphyrins in which the imidazole ring of the bound histidine assumes an eclipsed conformation with respect to the plane defined by the ligating nitrogen atom and the two diametrically opposite pyrrole nitrogens (Mashiko et al., 1981). Thus, it may be that the state I to state II transformation is accompanied by a transition from the staggered to the eclipsed conformation of the axial histidine, which may contribute to the large negative shift of the redox potential. Support for this conclusion is provided by the SERR spectra. As is indicated by the frequency upshifts of the spin-state marker bands, in state II the heme core is contracted by about $0.01 \AA$ compared to state I, which nicely corresponds to a similar core contraction of tailed porphyrins compared to normal 6cLS porphyrins (Mashiko et al., 1981).

In the $5 \mathrm{cHS}$ couple, the redox potential $(-0.31 \mathrm{~V})$ is not as low as in the 6cLS configuration. Most likely in this case and following Kassner (1972) the negative shift of the redox potential would exclusively result from the reduced hydrophobicity of the porphyrin environment due to the opening of the heme crevice.

Electrostatic Interactions in State I and State II. The potential of zero charge $\left(E_{\mathrm{pzc}}\right)$ of the $\mathrm{Ag}$ electrode lies between -0.65 and $-0.95 \mathrm{~V}$ (Valette \& Hamelin, 1973; Shlepakov et al., 1978). When the potential of the Ag electrode is set above $E_{\mathrm{pzc}}$, the metal surface carries a net positive charge that is overcompensated by specifically adsorbed anions (Bockris \& Reddy, 1970). A similar charge distribution in the electrical double layer is expected for the Ag electrode at open circuit or for $\mathrm{Ag}$ colloids since for the latter a potential of about -0.15 $V$ has been determined (Henglein \& Lilie, 1981) that is clearly above $E_{\mathrm{pzc}}$. At potentials above $E_{\mathrm{pzc}}$, the specifically adsorbed anions bind tightly to the $\mathrm{Ag}$ surface so that the accumulation of negatively charged organic molecules in the electrical double layer is strongly inhibited (Hildebrandt \& Stockburger, $1986 \mathrm{~b})$. On the other hand, the adsorption of positively charged or neutral molecules is favored or mediated by the specifically adsorbed anions.

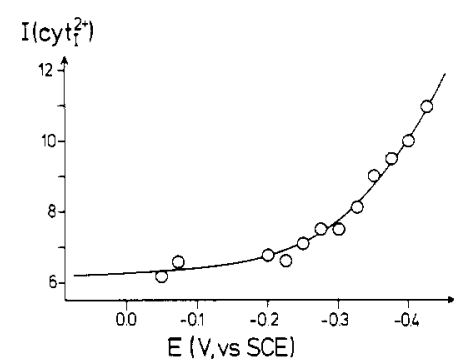

FIGURE 13: Dependence of the SERR intensity of $\nu_{4}$ of cyt ${ }_{\mathrm{I}}^{2+}$ on the electrode potential.

Cyt $c$ is a highly polar protein that, at neutral $\mathrm{pH}$, carries a net positive charge of $+8\left(\mathrm{cyt}^{2+}\right)$ or $+9\left(\mathrm{cyt}^{3+}\right)$ (Koppenol \& Margoliash, 1982). Thus, there are strong electrostatic interactions that govern the adsorption of cyt $c$ on the $\mathrm{Ag}$ electrode or on $\mathrm{Ag}$ colloids. This corresponds to the high free enthalpy of adsorption, which is $-56 \mathrm{~kJ} / \mathrm{M}$ on $\mathrm{Ag}$ sol (Hildebrandt \& Stockburger, 1986a). The electrostatic nature of the adsorption implies that the adsorption equilibrium of cyt $c$ is a function of the electrode potential. This is reflected by the potential dependence of the SERR intensity $\left(\nu_{4}\right)$ of cyt $_{\mathrm{I}}^{2+}$ that is plotted in Figure 13.

We have shown in the first section that above and below $-0.2 \mathrm{~V}$ two different conformational states are stabilized. This points to qualitatively different modes of adsorption in the two potential ranges. Evidently in the states I and II the protein is attached to the metal via different groups of amino acids. These groups constitute the thermodynamically preferred molecular binding sites in the two different potential ranges.

On the basis of this interpretation the conversion between the two states must proceed in two steps. First, the electrode-protein bonds are broken, and then the protein readsorbs to the electrode via different amino acids. The time scale of this conversion is about $2-3 \mathrm{~h}$. Since the adsorption occurs within seconds or faster, the desorption must be the rate-determining step. Therefore, we have determined the desorption rate in a separate experiment. For this purpose $\mathrm{cyt}_{\mathrm{II}}$ was at first adsorbed on the Ag electrode. Then the dissolved cyt $c$ was removed from the bulk solution in the electrochemical cell so that the adsorption equilibrium was distorted. To restore the adsorption equilibrium cyt $c$ molecules had to desorb from the surface. Hence, we monitored the SERR intensity as a function of time. From such data the desorption rate constant was inferred. A value of $1.5 \times 10^{-4} \mathrm{~s}^{-1}$ was obtained, which is of the same order of magnitude as the time scale of the conversion between state I and state II.

It is therefore not surprising that the conversion rate between the two states is much faster without rotating of the electrode. Under these conditions, the same spot of the surface is continuously irradiated by the exciting laser beam, leading to a heating of the sample. Thus, the desorption is considerably accelerated.

Now we ask for the molecular sites that bind cyt $c$ to the electrode surface in states I and II, respectively. Koppenol and Margoliash (1982) have shown that the positive end of the molecular dipole axis points to Phe-82, which is located close to the exposed heme edge and surrounded by a number of positively charged lysine residues. Furthermore, if these lysine residues are chemically modified so that the sign of their charge is reversed, no adsorption of cyt $c$ to electrodes was observed (Hill, 1987). These results can be taken as strong evidence that the lysine-rich domain is the part of the protein surface that interacts with the $\mathrm{Ag}$ electrode (colloids) at potentials above $E_{\mathrm{pzc}}$. Since in this potential range cyt ${ }_{1}$ as well as cyt ${ }_{\text {II }}$ are stabilized, it is concluded that in both states amino 


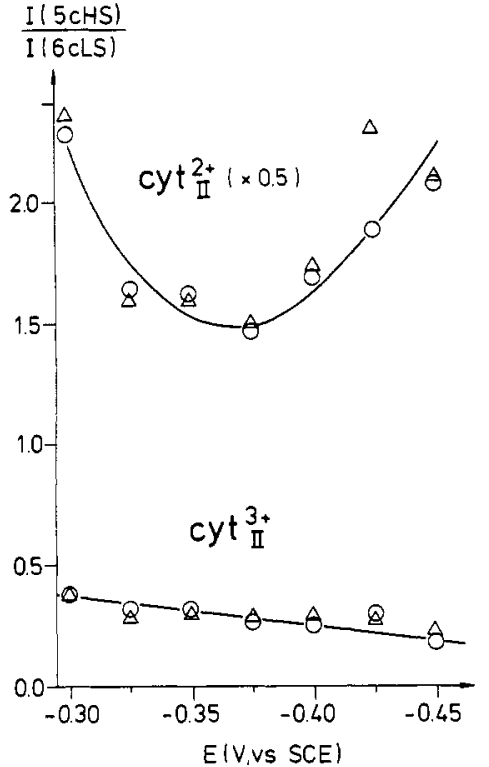

FIGURE 14: Potential dependence of the coordination equilibria in cyt $_{\text {II }}^{2+}$ (upper curve) and cyt $\mathrm{II}^{3+}$ (lower curve) in range $\mathrm{B}$. The triangles and circles are the values derived from the $\nu_{4}$ and $\nu_{3}$ band intensities, respectively. The values from $\nu_{3}$ are multiplied by $R$ according to eq 1.

acids that are located in the lysine-rich domain may serve as molecular anchors to the electrode. It may be that the adsorption is thermodynamically favored for different lysine residues at potentials above and below $-0.2 \mathrm{~V}$. This would imply that the orientation of cyt $c$ and the heme with respect to the electrode is different in the states I and II so that the heme binding pocket is subject to different electrostatic interactions in both states. Therefore, we ascribe the structural alterations in cyt $_{\text {II }}$ compared to cyt ${ }_{I}$ to modified electrostatic interactions in both modes of adsorption. While in state I they are too weak to cause any distortion in the protein structure, in state II they are strong enough to modify the coordination shell of the heme iron.

This conclusion is supported by the potential dependence of the coordination equilibria of state II, which is depicted in Figure 14. The shapes of the curves, which are quite different for cyt $\mathrm{II}_{\mathrm{II}}^{2+}$ and $\mathrm{cyt}_{\mathrm{II}}^{3+}$, demonstrate that there is no simple relationship between electrostatic interactions, which control structural modifications in state II, and the electrode potential. This can qualitatively be understood if one takes into account that both repulsive forces due to the positive charges on the metal surface and attractive forces due to the adsorbed anions contribute to the complex electrostatic interactions with the positively charged cyt $c$. Apparently, the two opposing effects do not uniformly vary with the potential, so that the electrostatic interactions that are operative for the structural distortion of the heme environment may exhibit minima and maxima as can be seen, for example, in the case of cyt $t_{\text {II }}^{2+}$. Also, the electrolyte dependence of the coordination equilibria in cyt $_{\text {II }}$ can readily be explained by electrostatic interactions with the charged electrode surface since the charge distribution in the electrical double layer strongly depends on the concentration and the kind of electrolyte. Thus, the spin-state distribution of the adsorbed cyt $\mathrm{t}_{\mathrm{II}}$ in the absence of an electrolyte changes drastically after addition of $\mathrm{Cl}^{-}$to the solution, while $\mathrm{F}^{-}$, which in contrast to $\mathrm{Cl}^{-}$does not adsorb specifically to the Ag surface (Valette \& Hamelin, 1972), has no effect on the SERR spectrum at all.

In the previous section we had argued that the structural changes in state II must be restricted to the immediate heme

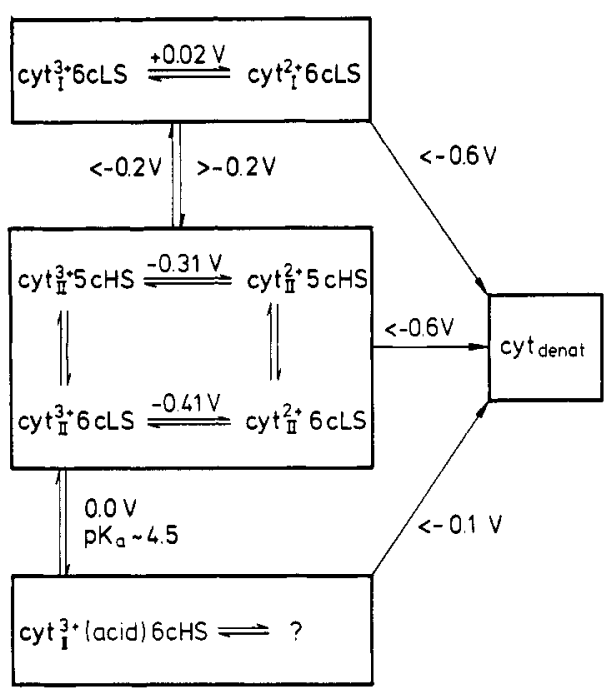

FIGURE 15: Overall reaction scheme of the potential-dependent processes of the adsorbed cyt $c$ on the $\mathrm{Ag}$ electrode.

environment. It may be that the primary effect is an electrostatic repulsion or attraction of the iron porphyrin moiety by the electrical field originating from the double layer in the $\mathrm{Ag} /$ electrolyte interface. Thus, the heme may be displaced with respect to the axial ligands so that the axial bonds are weakened. Such an interpretation may also explain why these coordination-state changes are observed in a variety of heme proteins with quite different protein structures, types of heme, and axial ligands (Hildebrandt \& Stockburger, 1986a, 1989a). The underlying electrostatic interactions are apparently independent of the protein matrix.

When the electrode potential approaches $E_{\mathrm{pze}}$, irreversible denaturation of the adsorbed cyt $c$ becomes an efficient process. Apparently, changing the sign of the charge of the electrode surface modifies the electrostatic interactions with the adsorbed cyt $c$ qualitatively. At $E_{\text {pzc }}$, the interactions of the metal surface with charged groups are weak but strong for neutral groups (Bockris \& Reddy, 1970). Thus, it may be that at this potential the attraction of neutral, more hydrophobic amino acids in the interior of the protein by the electrode becomes so strong that the secondary structure collapses and a direct contact of these residues with the electrode is achieved by the unfolding of the polypeptide chain.

State I and state II reveal a different stability against denaturation. While at $-0.4 \mathrm{~V}$ cyt $\mathrm{t}_{\mathrm{I}}^{2+}$ is stable for several hours, the data in Table II indicate that $\mathrm{cyt}_{\mathrm{II}}$ is converted to a small amount of the denatured cyt $c$ so that denaturation competes with the transition to state I up to potentials of $-0.3 \mathrm{~V}$. The acid form of cyt $\mathrm{II}_{\mathrm{II}}^{3+}$ at $\mathrm{pH} 2.0$ is even more labile since even at potentials of $-0.1 \mathrm{~V}$ the characteristic bands of the denatured cyt can be detected in the SERR spectra (spectra not shown).

Overall Redox Process of cyt $c$ at the Electrode/Electrolyte Interface. The reactions of the adsorbed cyt $c$ on the $\mathrm{Ag}$ electrode are summarized in Figure 15. The different electron-transfer pathways with redox potentials between +0.02 and $-0.41 \mathrm{~V}$ are coupled via the potential-dependent conformational equilibrium of state I and state II as well as the potential-dependent coordination equilibria within state II.

These findings are in sharp contrast to the concept of the electron-transfer mechanism of cyt $c$ on electrodes that was originally proposed by Albery et al. (1981). It is based on the assumption that the adsorbed cyt $c$ is identical with the native cyt $c$ in solution so that the electron transfer takes place via a single pathway. Thus, deviations from the Nernstian behavior or from the expected redox potential that had been 
found in several electrochemical studies were always attributed to the denaturation of the adsorbed protein. On the basis of the present paper, some of the electrochemical experiments may be reinterpreted in terms of a distribution among different conformational states of the adsorbed cyt $c$ [for a review on the electrochemistry of cyt $c$ see Bowden et al. (1985)].

For the comparison of electrochemical and SERR experiments one has to take into account that SERR spectroscopy selectively probes the adsorbed molecules, whereas electrochemical techniques monitor the reactions of the bulk species with the electrode. Thus, both techniques may provide quite different results even when the same experimental conditions are employed. An instructive example for this discrepancy results from a recent cyclic voltammetry (CV) study of cyt $c$ with an Ag electrode by Reed and Hawkridge (1987). These authors have nicely demonstrated that a quasi-reversible CV response during a period of more than $12 \mathrm{~h}$ could be obtained only when chromatically purified cyt $c$ was used. The midpoint potential was found at $+0.01 \mathrm{~V}$. Addition of crude cyt $c$, which includes deamidated forms of the protein, inhibited the reversible reaction. These findings were interpreted in terms of irreversible blocking of the Ag surface by the deamidated molecules. To correlate these results with our SERR experiments, we analyzed the SERR spectra after repetitive cycling of the potential using the same experimental conditions at Reed and Hawkridge (1987) except for a 2000 times lower concentration of cyt $c$. It turned out that, although the experiment was started with pure cyt $\mathrm{I}_{I}$ and cycling was carried out without laser illumination, after three cycles already about $60 \%$ of the adsorbed cyt $c$ had been converted to state II. This implies that a quasi-reversible $C V$ response with a redox potential of the dissolved cyt $c$ is possible even if a large portion of the adsorbed cyt $c$ is in state II that exhibits redox potentials at -0.31 and $-0.41 \mathrm{~V}$. Therefore, one has to conclude that the oxidation and reduction of the bulk cyt $c$ at the electrode does not proceed via the strongly adsorbed cyt $c$ but must occur at different sites of the surface.

In this context it is interesting to refer to suggestions made by Kusznetsov (1981) and Scheller (1977). They proposed that electron transfer to the bulk species occurs via pores of a layer formed by irreversibly adsorbed cyt $c$ molecules. Following this picture it is evident that $\mathrm{CV}$ and other electrochemical techniques probe the redox process at the pores, while SERR spectroscopy exclusively reflects the reactions of the strongly adsorbed molecules. When the pores are blocked by deamidated cyt $c$ molecules, the $\mathrm{CV}$ response becomes irreversible but the SERR spectroscopic results are not affected. Therefore, it is not surprising that crude and purified cyt $c$ turned out to behave identically in SERR but not in CV experiments.

Finally, we refer to previous SERR studies of cyt $c$ on the Ag electrode. In the first work by Cotton et al. (1980) SERR spectra of cyt $c$ were presented that at -0.2 and $-0.6 \mathrm{~V}$ reveal the oxidized and the reduced cyt $c$, respectively. In the latter, marker bands for both the $6 \mathrm{cLS}$ and the $5 \mathrm{cHS}$ configurations are detectable. Evidently, these spectra reflect state II. The same interpretation may hold for the studies by Taniguchi et al. (1984) and Niki et al. $(1986,1987)$. It is interesting to note that Niki et al. $(1986,1987)$ estimated the apparent redox potential of adsorbed cyt $c$ on the basis of the SERR spectra. The value of $-0.38 \mathrm{~V}$ is just in the range of the redox potentials of $\mathrm{cyt}_{\mathrm{II}}$ determined in this paper.

\section{CONCLUSIONS}

In the present study it was shown that the electron-transfer reactions of adsorbed cyt $c$ on electrodes can proceed via different pathways that are associated with different cyt $c$ species. The structures of these species and the transitions between them are controlled by electrostatic interactions in the electrical double layer of the electrode. There is no evidence that specific $\mathrm{Ag}-\mathrm{cyt} c$ interactions play any role in these conformational transitions. Thus, they should occur not only on the $\mathrm{Ag}$ electrode but also at other charged interfaces as far as the electrostatic interactions are comparable. This will indeed be shown in the subsequent paper (Hildebrandt \& Stockburger, 1989b).

Furthermore, it was demonstrated that SERR spectroscopy can give insight into the electron-transfer reactions of adsorbed species and thus provide complementary information compared to conventional electrochemical methods.

\section{ACKNOWLEDGMENTS}

We thank Prof. A. Weller for encouragement and support. We gratefully acknowledge the purification of cyt that was carried out by Dr. H. Garda.

\section{APPENDIX}

Evaluation of the Relative Concentrations of the Adsorbed cyt $c$ Species. The total concentration of the adsorbed cyt, $C_{0}(E)$, is related to SERR intensities of the individual species according to

$$
C_{0}(\mathrm{E})=\sum_{i} f_{i} I_{i}(\mathrm{E})
$$

where $f_{i}$ is defined in eq 2. The potential dependence of $C_{0}(\mathrm{E})$ can be approximated by the data obtained for cyt ${ }_{1}^{2+}$ (Figure 13). Furthermore, it is reasonable to assume that due to the structural similarity the ratio of the $f_{i}$ values of cyt $t_{\mathrm{I}}^{2+}$ and cyt $_{\mathrm{I}}^{3+}$ is the same as for cyt $\mathrm{N}_{\mathrm{N}}^{2+}$ and $\mathrm{cyt}_{\mathrm{N}}^{3+}$ since the structure of state $\mathrm{I}$ is the same as of the dissolved cyt $_{\mathrm{N}}$. This ratio was determined in a RR experiment to be 0.313 . Then the intensities $I_{i}(\mathrm{E})$ of the potential range $\mathrm{A}$ as listed in Table II can be fitted to eq $\mathrm{Al}$ on the basis of four adjustable parameters. For the determination of the remaining four $f_{i}$ values we used an additional constraint. Following the reaction scheme in Figure 11 the equilibrium constants of the coordination equilibria

$$
\begin{aligned}
K_{\mathrm{S}, \mathrm{R}} & =\left[\mathrm{cyt}_{\mathrm{II}}^{2+} 6 \mathrm{cHS}\right] /\left[\mathrm{cyt}_{\mathrm{II}}^{2+} 6 \mathrm{cLS}\right] \\
K_{\mathrm{S}, O} & =\left[\mathrm{cyt}_{\mathrm{II}}^{3+} 5 \mathrm{cHS}\right] /\left[\mathrm{cyt}_{\mathrm{II}}^{3+} 6 \mathrm{cLS}\right]
\end{aligned}
$$

must be related to the redox equilibria according to the law of conservation of energy; i.e., eq A4 must be valid for all potentials

$$
K_{\mathrm{S}, \mathrm{R}} \exp \left[\frac{n F}{R T}\left(E_{\mathrm{II}, \mathrm{L}}^{0}-E\right)\right]=K_{\mathrm{S}, \mathrm{O}} \exp \left[\frac{n F}{R T}\left(E_{\mathrm{II}, \mathrm{H}}^{0}-E\right)\right]
$$

Combination of eq A2-A4 leads to

$$
\begin{array}{r}
\ln \left[\frac{I\left(\mathrm{cyt}_{\mathrm{II}}^{2+} 6 \mathrm{cLS}\right) I\left(\mathrm{cyt}_{\mathrm{II}}^{3+} 5 \mathrm{cHS}\right)}{I\left(\mathrm{cyt}_{\mathrm{II}}^{2+} 5 \mathrm{cHS}\right) I\left(\mathrm{cyt}_{\mathrm{II}}^{3+} 6 \mathrm{cLS}\right)}\right]+\frac{n F}{R T}\left(E_{\mathrm{II}, \mathrm{H}}^{0}-E_{\mathrm{II}, \mathrm{L}}^{0}\right)= \\
\ln \left[\frac{f\left(\mathrm{cyt}_{\mathrm{II}}^{2+} 5 \mathrm{cHS}\right) f\left(\mathrm{cyt}_{\mathrm{II}}^{3+} 6 \mathrm{cLS}\right)}{f\left(\mathrm{cyt}_{\mathrm{II}}^{2+} 6 \mathrm{cLS}\right) f\left(\mathrm{cyt}_{\mathrm{II}}^{3+} 5 \mathrm{cHS}\right)}\right]=C(\mathrm{~A} 5)
\end{array}
$$

The experimental data yield $C=1.35 \pm 0.06$. Inserting the $f_{i}$ values for cyt $\mathrm{II}_{\mathrm{II}}^{3+} 6 \mathrm{cLS}$ and $\mathrm{cyt}_{\mathrm{II}}^{3+} 5 \mathrm{cHS}$ determined from the potential range $A$, one obtains

$$
f\left(\mathrm{cyt}_{\mathrm{II}}^{2+} 5 \mathrm{cHS}\right) / f\left(\mathrm{cyt}_{\mathrm{II}}^{2+} 6 \mathrm{cLS}\right)=7.7
$$

Then the intensities of the potential range $B$ can be fitted to eq $\mathrm{A} 1$ by using three adjustable parameters. The so obtained $f_{i}$ values are listed in Table II. The accuracy of the $f_{i}$ de- 
termination is estimated to be about $10 \%$. It should be mentioned that even an error of $\pm 20 \%$ would lead to an error of only $\pm 0.01 \mathrm{~V}$ for the determination of $E_{0}$ according to eq 3.

Registry No. Cytochrome $c$, 9007-43-6.

\section{REFERENCES}

Albery, W. J., Eddowes, M. J., Hill, H. A. O., \& Hillman, A. R. (1981) J. Am. Chem. Soc. 103, 3904.

Alshuth, Th. (1985) Ph.D. Thesis, Universität Göttingen.

Ångström, J., Moore, G. R., \& Williams, R. J. P. (1982) Biochim. Biophys. Acta 703, 87.

Bockris, J. O. M., \& Reddy, A. K. N. (1970) Modern Electrochemistry, Vol. 2, p 748, Plenum Press, New York.

Bowden, E. F., Hawkridge, F. M., \& Blount, H. N. (1985) in Comprehensive Treatise of Electrochemistry (Srinivasan, S., Chiznadzhiev, Yu. A., Bockris, J. O. M., Conway, B. E., \& Yeager, E., Eds.) Chapter 5, Plenum Press, New York.

Brautigan, D. L., Ferguson-Miller, S., \& Margoliash, E. (1978) Methods Enzymol. 53D, 131.

Choi, S., \& Spiro, T. G. (1983) J. Am. Chem. Soc. 105, 3683.

Cotton, T. M. (1985) in Surface and Interfacial Aspects of Biomedical Polymers (Andrade, J. D., Ed.) Vol. II, p 161, Plenum Press, New York.

Cotton, T. M. (1988) in Spectroscopy of Surfaces (Clark, R. J. H., \& Hester, R. E., Eds.) p 91, Wiley, New York.

Cotton, T. M., Schultz, S. G., \& Van Duyne, R. P. (1980) J. Am. Chem. Soc. 102, 7960.

Cotton, T. M., Timkovich, R., \& Cork, M. S. (1981) FEBS Lett. 133, 39.

Cusanovich, M. A., Meyer, T. E., \& Tollin, G. (1988) $A d v$. Inorg. Biochem. 7, 37.

de Groot, J., \& Hester, R. E. (1987) J. Phys. Chem. 91, 1693.

de Groot, J., Hester, R. E., Kaminaka, S., \& Kitagawa, T. (1988) J. Phys. Chem. 92, 2044.

Dickerson, R. E., \& Timkovich, R. (1975) in The Enzymes (Boyer, P. D., Ed.) Vol. XIA, p 397, Academic Press, New York.

Fraser, R. D. B., \& Suzuki, E. (1970) in Spectral Analysis: Methods and Techniques (Blackburn, J. A., Ed.) p 171, Dekker, New York.

Henglein, A., \& Lilie, J. (1981) J. Am. Chem. Soc. 103, 1059.

Hildebrandt, P., \& Stockburger, M. (1986a) J. Phys. Chem. $90,6017$.

Hildebrandt, P., \& Stockburger, M. (1986b) J. Raman Spectrosc. 17, 55.

Hildebrandt, P., \& Stockburger, M. (1989a) Vib. Spectra Struct. 17 A, 443-466.

Hildebrandt, P., \& Stockburger, M. (1989b) Biochemistry (following paper in this issue).

Hildebrandt, P., Greinert, R., Stier, A., Stockburger, M., \& Taniguchi, H. (1988a) FEBS Lett. 227, 76.

Hildebrandt, P., Macor, K. A., \& Czernuszewicz, R. S. (1988b) J. Raman Spectrosc. 19, 65.

Hill, H. A. O. (1987) Pure Appl. Chem. 59, 743-748.

Kassner, R. J. (1972) Proc. Natl. Acad. Sci. U.S.A. 69, 2263.

Kelly, K., Rospendowski, B. N., Smith, W. E., \& Wolf, C. R. (1987) FEBS Lett. 222, 120.

Kitagawa, T., \& Ozaki, Y. (1987) Struct. Bonding 64, 71.
Koglin, E., \& Séquaris, J.-M. (1986) Top. Curr. Chem. 134, 1 .

Koppenol, W. H., \& Margoliash, E. (1982) J. Biol. Chem. $257,4426$.

Korszun, Z. R., Moffat, K., Frank, K., \& Cusanovich, M. A. (1982) Biochemistry 21, 2253.

Kuznetsov, B. A. (1981) Bioelectrochem. Bioenerg. 8, 681.

Mashiko, T., Reed, C. A., Haller, K. J., Kastner, M. E., \& Scheidt, W. R. (1981) J. Am. Chem. Soc. 103, 5758.

Neumann, E. (1981) Top. Bioelectrochem. Bioenerg. 4, 113-160.

Niki, K., Kawasaki, Y., Hinnen, C., Higuchi, Y., \& Yasuoka, N. (1986) in Frontiers in Bioorganic Chemistry (Xavier, A. V., Ed.) p 622, Verlag Chemie, Weinheim, FRG.

Niki, K., Kawasaki, Y., Kimura, Y., Higuchi, Y., \& Yasuoka, N. (1987) Langmuir 3, 982.

Parthasarathi, N., Hansen, C., Yamaguchi, S., \& Spiro, T. G. (1987) J. Am. Chem. Soc. 109, 3865.

Pettigrew, G. W., \& Moore, G. R. (1987) Cytochrome CBiological Aspects, Chapter 2, Springer Verlag, Berlin.

Reed, D. E., \& Hawkridge, F. M. (1987) Anal. Chem. 59, 2334.

Rein, H., Jung, C., Ristau, O., \& Friedrich, J. (1984) in Cytochrome P-450 (Ruckpaul, K., \& Rein, H., Eds.) Chapter 4, Akademie Verlag, Berlin.

Remba, R. D., Champion, P. M., Fitchen, D. B., Chiang, R., \& Hager, L. P. (1979) Biochemistry 18, 2280.

Rieder, R., \& Bosshard, H. R. (1980) J. Biol. Chem. 255, 4732.

Salemme, F. R. (1977) Annu. Rev. Biochem. 46, 299.

Scheller, F. (1977) Bioelectrochem. Bioenerg. 4, 490.

Schmidt, P. P., Seversen, M., Korzeniewski, C., \& Pons, S. (1987) J. Electroanal. Chem. Interface Sci. 225, 267.

Shlepakov, A. V., \& Serast'yanov, E. S. (1978) Elektrokhimiya (Engl. Transl.) 14, 243.

Smith, H. T., Staudenmayer, N., \& Millet, F. (1977) Biochemistry 16, 4971 .

Smulevich, G., \& Spiro, T. G. (1985) J. Phys. Chem. 89, 5168.

Speck, H. S., Ferguson-Miller, S., Osheroff, N., \& Margoliash, E. (1979) Proc. Natl. Acad. Sci. U.S.A. 76, 155.

Spiro, T. G. (1983) in Iron Porphyrins (Lever, A. B. P., \& Gray, H. B., Eds.) Part II, p 89, Addison-Wesley, Reading, MA.

Taniguchi, I., Iseki, M., Yamaguchi, H., \& Yasukouchi, K. (1984) J. Electroanal. Chem. Interface Sci. 175, 341.

Theorell, H., \& A kesson, A. (1941) J. Am. Chem. Soc. 63, 1812.

Valance, W. G., \& Strekas, T. C. (1982) J. Phys. Chem. 86, 1804.

Valette, G., \& Hamelin, A. (1973) J. Electroanal. Chem. Interface Sci. 45, 301.

Vanhecke, F., \& Heremans, K. (1988) in The Spectroscopy of Biological Molecules-New Advances (Schmidt, E. D., Siebert, F., \& Schneider, F. W., Eds.) p 343, Wiley, New York.

Weber, C., Michel, B., \& Bosshard, H. R. (1987) Proc. Natl. Acad. Sci. U.S.A. 84, 6687.

Wolf, C. R., Miles, J. S., Seilman, S., Burke, M. D., Rospendowski, B. N., Kelly, K., \& Smith, W. E. (1988) Biochemistry 27, 1597. 